\title{
Phylogenetics of Panicoideae (Poaceae) based on chloroplast and nuclear DNA sequences
}

\author{
Atchara Teerawatananon ${ }^{1,2}$ Surrey W.L. Jacobs ${ }^{3 \dagger}$ and \\ Trevor R. Hodkinson ${ }^{2}$
}

\author{
${ }^{1}$ Natural History Museum of Thailand, National Science Museum, \\ Technopolis, Pathum Thani 12120, Thailand \\ ${ }^{2}$ School of Natural Sciences, Botany Building, Trinity College Dublin, \\ University of Dublin, Dublin 2, Ireland \\ ${ }^{3}$ National Herbarium of New South Wales, Royal Botanic Gardens, Mrs Macquaries Road, Sydney, \\ New South Wales 2000, Australia \\ Author for correspondence: teerawaa@gmail.com
}

\begin{abstract}
Phylogenetic relationships among major subfamilies in Poaceae and among major tribes within Panicoideae were evaluated using parsimony and Bayesian analyses of chloroplast $\operatorname{trn} \mathrm{L}-\mathrm{F}$ and $a t p \beta-r b c L$ DNA sequences and a nuclear ribosomal DNA sequence, ITS1-ITS2. The PanicoideaeAristidoideae-Chloridoideae-Micrairoideae-Arundinoideae-Danthonioideae (PACMAD) clade was well resolved. A close relationship between Aristidoideae and Chloridoideae was found. The monophyly of Micrairoideae was resolved but the relationships of three tribes (Eriachneae, Isachneae, Micraireae) within Micrairoideae were unclear, only Eriachne and Isachne were monophyletic. Panicoideae sensu stricto were supported as monophyletic and sister to a clade of Danthoniopsis and Tristachya. Within Panicoideae, only a clade of Andropogoneae + Arundinella + Garnotia was supported. None of the analyses supported the monophyletic status of Paniceae. Within Paniceae, the bristle clade (excluding Cenchrus) + Alexfloydia, and the forest shade clade sensu Giussani et al. (2001), were found, but their circumscription remains ambiguous. A sister relationship between the endemic and rare Australian grasses Homopholis and Walwhalleya was also resolved. Arundinelleae were found to be polyphyletic. This study supported the separation of Arundinella and Garnotia from the remaining Arundinelleae and the inclusion of both genera in their own subtribes (Arundinellinae Honda sensu stricto and Garnotiinae Pilger) within the Andropogoneae. Arundinelleae should be abandoned as a taxonomic tribe within the Centothecoid + Panicoid clade. Within Andropogoneae, five out of a total of 11 subtribes (Chionachninae, Coicinae, Dimeriinae, Germainiinae, and Tripsacinae) were monophyletic. This was the first time that Dimeriinae and Germainiinae have been included in a molecular study.
\end{abstract}

\footnotetext{
${ }^{\dagger}$ Deceased November 262009.
} 


\section{Introduction}

Panicoideae are one of the biggest subfamilies in Poaceae, comprising approximately 3,000 species and 200 genera (GPWG 2001). Although Panicoideae are highly diverse, all members can be grouped on the basis of the presence of two-flowered spikelets with male or sterile lower florets (Clayton \& Renvoize 1986, Kellogg 2000) and simple type starch grains in the endosperm (Tateoka 1962). These spikelet and starch grain types were described as uniquely-derived characters by Kellogg and Campbell (1987). The monophyly of Panicoideae has also been verified by many molecular studies using chloroplast and nuclear DNA (e.g., Barker et al. 1999, Gomez-Martinez \& Culham 2000, Giussani et al. 2001, GPWG 2001, Aliscioni et al. 2003, Bouchenak-Khelladi et al. 2008, Christin et al. 2008, Vicentini et al. 2008, Edwards \& Smith 2010). In the widely used classification system of Clayton and Renvoize (1986), Panicoideae were split into seven tribes: Andropogoneae, Paniceae, Arundinelleae, Isachneae, Hubbardieae, Steyermarkochloeae and Eriachneae. Subsequently, Panicoideae were divided into two groups using phenetic analyses: the Andropogoneae + Garnotieae group and the Paniceae + Isachneae + Arundinelleae group of Hilu and Wright (1982) and the supertribes Panicodae and Andopogonodae of Watson and Dallwitz (1992 onwards). More recent phylogenetic analyses have resolved six tribes in Panicoideae because Eriachneae were placed outside Panicoideae as incertae sedis (GPWG 2001). Two tribes, Eriachneae and Isachneae, were placed together with Micraireae in a new subfamily Micrairoideae (Sánchez-Ken et al. 2007).

Over the past few decades, members of Arundinelleae have been included in several phylogenetic analyses. According to the morphological phylogenetic reconstruction of Kellogg and Watson (1993), Arundinelleae (excluding Garnotia) were monophyletic. In contrast, several analyses of DNA sequences resolved Arundinelleae as polyphyletic and suggested that its delimitation should be reconsidered (Barker et al. 1999, Hilu et al. 1999, Spangler et al. 1999, GPWG 2001, Sánchez-Ken \& Clark 2007, Sánchez-Ken et al. 2007, Bouchenak-Khelladi et al. 2008, Christin et al. 2008, Vicentini et al. 2008).

Andropogoneae are one of the two major tribes in Panicoideae. Based on morphology, this group of tropical grasses is well-defined containing more than 900 species with extensive morphological variation among its members (Clayton \& Renvoize 1986, GPWG 2001). Two widely used classifications of Andropogoneae come from the studies of Clayton and Renvoize (1986) and Watson and Dallwitz (1992 onwards). Andropogoneae were found to be non-monophyletic in the morphology based phylogenetic reconstruction of Kellogg and Watson (1993). Molecular data, on the other hand, consistently supported the monophyly of Andropogoneae as circumscribed by Clayton and Renvoize (1986), and also supported the sister relationship of Andropogoneae to Arundinella (e.g., Spangler et al. 1999, Mathews et al. 2002, Bomblies \& Doebley 2005, Sánchez-Ken \& Clark 2007, Sánchez-Ken et al. 2007, Christin et al. 2008, Vicentini et al. 2008). Even though many molecular results have supported the monophyly of the tribe, the identity and relationships of its subtribes are not well understood. Recent phylogenetic analyses have suggested that the short branches along the backbone of their trees and the concentration of nucleotide changes on terminal branches in the Andropogoneae clade have been caused by a rapid evolutionary radiation near the base of the clade (Kellogg 2000, Mathews et al. 2002, Skendzic et al. 2007). Many of these studies suggested that better sampling of lineages within the tribe, or the addition of more phylogenetic characters (more nucleotides), may help to resolve the relationships. 
The major objective of this study was to improve phylogenetic understanding within Panicoideae and among subfamilies in the PACMAD clade by increasing the sampling of taxa and by using plastid ( $\operatorname{trn} \mathrm{L}$ intron, $\operatorname{trn} \mathrm{L}-\mathrm{F}$ intergenic spacer, and the $a t p \beta-r b c \mathrm{~L}$ intergenic spacer) and nuclear (ITS) DNA sequences separately and in combination. The $a t p \beta-r b c \mathrm{~L}$ spacer was used for the first time to study inter-relationships of taxa within this group of plants. It also aimed to apply the results of the molecular phylogenies to taxonomy by testing the infra-subfamilial classification proposed by several authors. More specifically, it aimed to: (1) resolve major groupings within Panicoideae and investigate their inter-relationships, (2) investigate the monophyly of tribes of Panicoideae sensu Clayton and Renvoize (1986) and (3) investigate the subtribal classification of Andropogoneae.

\section{Material and Methods}

\section{Taxonomic sample}

The majority of the materials were collected during our expeditions within several regions of Thailand, South America and Australia. Leaf material was dried with silica gel to rapidly desiccate the material and reduce DNA degradation before extraction (Chase \& Hills 1991) or with the alternative preservative solution of saturated CTAB to reduce degradative changes affecting the quality of DNA (Thomson 2002). A few samples were taken from herbarium specimens and some DNA was available in the Botany Molecular Laboratory, Trinity College, Dublin and the Royal Botanic Gardens, Kew, England, U.K. The sample of species presented in this study relied greatly on the Old World grasses, especially the panicoid group. Additional taxa of other subfamilies from the New World and Australasia were also included. Five out of a total of seven tribes of Panicoideae sensu Clayton and Renvoize (1986) were sampled. The number of panicoid species presented here is considerably larger than most molecular studies to date. However, representatives of the two small tribes, Steyermarkochloeae and Hubbardieae, were not included due to the lack of material suitable for DNA extraction. In total, 132 taxa from six subfamilies sensu Clayton and Renvoize (1986), including 10 other taxa of subfamilies Centothecoideae, Arundinoideae and Chloridoideae, and five tribes of Panicoideae and all subtribes of Andropogoneae were sampled. This was the first time that Dimeriinae and Germainiinae have been included in a molecular study (Appendix 1). Five grasses from Ehrhartoideae and Pooideae were chosen as outgroup taxa, according to the results of GPWG (2001) and Bouchenak-Khelladi et al. (2008). For the trnL-F region, 13 taxa out of a total of 129 taxa were downloaded from GenBank (http://www.ncbi.nlm.nih.gov). For the atp $\beta-r b c \mathrm{~L}$ region, we sequenced 122 taxa and downloaded five sequences from GenBank. For the ITS region, 127 taxa were sampled, including 27 sequences from GenBank. In total, 124 taxa were included in the combined dataset.

\section{DNA extraction, amplification and sequencing}

Total genomic DNA (tDNA) was extracted using a modified hot CTAB (hexadecyltrimethylammonium bromide) method of Doyle and Doyle (1987) as outlined in Hodkinson et al. (2007b). The extractions used $0.2 \mathrm{~g}$ of dried leaf or $0.3 \mathrm{~g}$ of material obtained from herbarium specimens. The extract was precipitated using isopropanol and kept at $-20{ }^{\circ} \mathrm{C}$ overnight or for three weeks to increase precipitation 
in the case of herbarium specimens. The total DNA samples were then washed and purified with $70 \%$ ethanol and further purified by using JETquick spin columns (GENOMED-GmbH, Löhne, Germany). The DNA was then transferred into a $1.5 \mathrm{ml}$ micro-centrifuge tube and stored at $-20^{\circ} \mathrm{C}$ until used or at $-80{ }^{\circ} \mathrm{C}$ for longer periods. The Polymerase Chain Reaction (PCR) was used to amplify two regions of chloroplast genome DNA, $\operatorname{trn} \mathrm{L}-\operatorname{trn\mathrm {F}}$ and $a t p \beta-r b c \mathrm{~L}$, and one region of nuclear ribosomal DNA, ITS. The $t r n \mathrm{~L}$ intron and $t r n \mathrm{~L}-\mathrm{F}$ intergenic spacer were amplified as a single fragment using the ' $c$ ' and ' $\mathrm{f}$ ' primers of Taberlet et al. (1991), the atp $\beta-r b c \mathrm{~L}$ region with the primers of Samuel et al. (1997) and the ITS region using the 17SE and 26SE primers of Sun et al. (1994). All of the amplifications were carried out in an Applied Biosystems GeneAmp ${ }^{\circledR}$ PCR System 9700 thermal cycler. The amplification of the target fragment began with an initial pre-melt at $94^{\circ} \mathrm{C}$ for $1 \mathrm{~min}$, followed by 29 cycles of denaturation at $95^{\circ} \mathrm{C}$ for $45 \mathrm{~s}$, annealing at $50^{\circ} \mathrm{C}$ for $\operatorname{trn} \mathrm{L}-\mathrm{F}$ or $52^{\circ} \mathrm{C}$ for $a t p \beta-r b c \mathrm{~L}$ and ITS for $45 \mathrm{~s}$, and extension at $72^{\circ} \mathrm{C}$ for $2 \mathrm{~min}$. A final extension at $72^{\circ} \mathrm{C}$ for $7 \mathrm{~min}$ was also included. All successful PCR products were purified using the same procedure as the total DNA purification but using sterile ultra pure water as the elution buffer. DNA was sequenced using BigDye Terminator v. 1.1 cycle-sequencing kits (Applied Biosystems) and an Applied Biosystems 310 automated DNA sequencer.

\section{Phylogenetic analyses}

Full sequences of all taxa listed in Appendix 1 were obtained. DNA sequences were checked and aligned by inserting gaps manually using Se-Al v. 2.0a11 (Rambaut 1996) following the guidelines of Kelchner (2000) and Baldwin et al. (1995) for the ITS matrix. Gaps smaller than 10 bp were coded as missing data, unless they were found in regions where there was an obvious tandemly arranged duplication in one sequence that was clearly due to a single mutation (a duplication). Such duplications were scored as only one character in the subsequent phylogenetic analyses. Gaps larger than $10 \mathrm{bp}$ were excluded from the analyses. For the ITS matrix, some taxa had some polymorphic nucleotide sites and at these sites the dominant peak was chosen or alternatively the site was excluded from the matrix if a single dominant peak was not present. The aligned sequences were imported into PAUP* v.4.0b10 (Swofford 2002).

Maximum parsimony (hereafter MP) analyses of the final matrix were performed using the heuristic search algorithms of PAUP ${ }^{\star}$ with 1,000 replicates of random addition sequence (holding 20 trees at each replication) and with tree bisection reconnection branch swapping on multiple trees. Clade support was examined using 1,000 bootstrap replicates (Felsenstein 1985) with the same settings as the initial heuristic search but with simple sequence addition instead of random sequence addition. Bayesian inference (hereafter BI) of the phylogeny was performed using MrBayes version 3.2 (Huelsenbeck \& Ronquist 2001). The appropriate nucleotide substitution models for BI analysis were chosen using hierarchical likelihood ratio tests as implemented in MODELTEST 3.06 (Posada \& Crandall 1998). The three datasets, two plastid and one nuclear, showed the same best-fit nucleotide substitution model $(G T R+G+I)$. Four parallel Markov chain Monte Carlo (MCMC) chains were run for 25,000,000 generations with trees sampled every 1,000 generations, and $25 \%$ of trees were discarded as burn-in. 


\section{Results}

\section{Analyses of the combined dataset}

The matrix used for the combined analysis was obtained from $\operatorname{trn} \mathrm{L}-\operatorname{trn} \mathrm{F}$, $a \operatorname{tp} \beta-r b c \mathrm{~L}$ and ITS sequences. The final aligned matrix was 3,348 bp long; 969 characters were constant, 288 were variable but parsimony-uninformative, and 682 characters were parsimony-informative. The tree search using maximum parsimony generated 687 equally most parsimonious trees of 4,330 steps with consistency index (CI) of 0.365 and retention index (RI) of 0.626. Bootstrap percentages (hereafter BP) are described as low (50-74 BP), moderate (75-84 BP) and high (85-100 BP). The MP analysis produced a topology that was congruent with the tree obtained from the BI analysis. By this we mean that there were no strongly supported groups in one analysis that were incongruent with strongly supported alternative groupings in the other analysis (no hard incongruence; following Reeves et al. 2001). The tree illustrated in Figure 1 is the Bayesian tree with the posterior probability $(\mathrm{PP})$ values obtained from the $\mathrm{BI}$ analysis and with bootstrap percentages from the separate MP bootstrap analysis. The tree is largely consistent with the combined plastid tree (Appendix 2, Fig. S1) and the ITS tree (Appendix 2, Fig. S2). We therefore base discussion of our results on the combined tree but occasionally refer to the supplementary information where appropriate.

The PACMAD clade was strongly supported (99 BP, 1.00 PP). Aristida (Aristidoideae) was sister to Chloridoideae (support for the monophyly of this subfamily was $81 \mathrm{BP}$, $1.00 \mathrm{PP}$ ) with $100 \mathrm{BP}$ and $0.96 \mathrm{PP}$. The position of this clade was unresolved in the BI tree but it was sister to a Micrairoideae clade, consisting of a monophyletic Eriachneae (100 BP, 1.00 PP) and an unresolved Isachneae (as the position of Coelachne was unresolved), in the strict consensus tree of the MP analysis (not shown). In the BI tree the Micrairoideae clade was sister to Arundo with $0.92 \mathrm{PP}$, but unresolved relative to Danthonioideae, Chloridoideae and a clade represented by the rest of the grasses. The PACCMAD group (including "Centothecoideae", in contrast to PACMAD) was not supported because Centothecoideae were paraphyletic with Panicoideae. However, support for the monophyly of a Centotheca + Thysanolaena clade was high (99 BP, 1.00 $\mathrm{PP})$. This reduced centothecoid clade was sister to a lineage, containing ((Panicoideae + Arundinelleae) + Chasmanthium) with 1.00 PP in the BI analysis, or was sister to a lineage consisting of Panicoideae + Arundinelleae, in the strict consensus tree of the MP analysis (not shown).

Arundinelleae were polyphyletic because Arundinella and Garnotia were included within Panicoideae (69 BP, 1.00 PP), while Danthoniopsis and Tristachya were grouped together with low support ( $55 \mathrm{BP}, 0.94 \mathrm{PP}$ ) and were placed as the next most outlying branch to the rest of Panicoideae. Paniceae were not supported or retrieved in the strict consensus tree in the MP analysis, but the BI analysis resolved the monophyly of Paniceae with 0.66 PP. None of the subtribes of Paniceae sensu Clayton and Renvoize (1986) were found to be monophyletic.

The combined dataset analyses supported two genera of Paniceae as monophyletic: Pennisetum (74 BP, 1.00 PP) and Sacciolepis (100 BP, 1.00 PP). The Pennisetum clade was sister to Setaria (51 BP, $0.71 \mathrm{PP}$ ). This clade was sister to a group consisting of Alexfloydia and Spinifex (support for the monophyly of this clade was 90 BP, 1.00 PP) with strong support (100 BP, 1.00 PP). Homopholis was sister to Walwhalleya (57 BP, $1.00 \mathrm{PP}$ ). Cyrtococcum, Pseudoechinolaena, and Acroceras were grouped together (57 BP, 


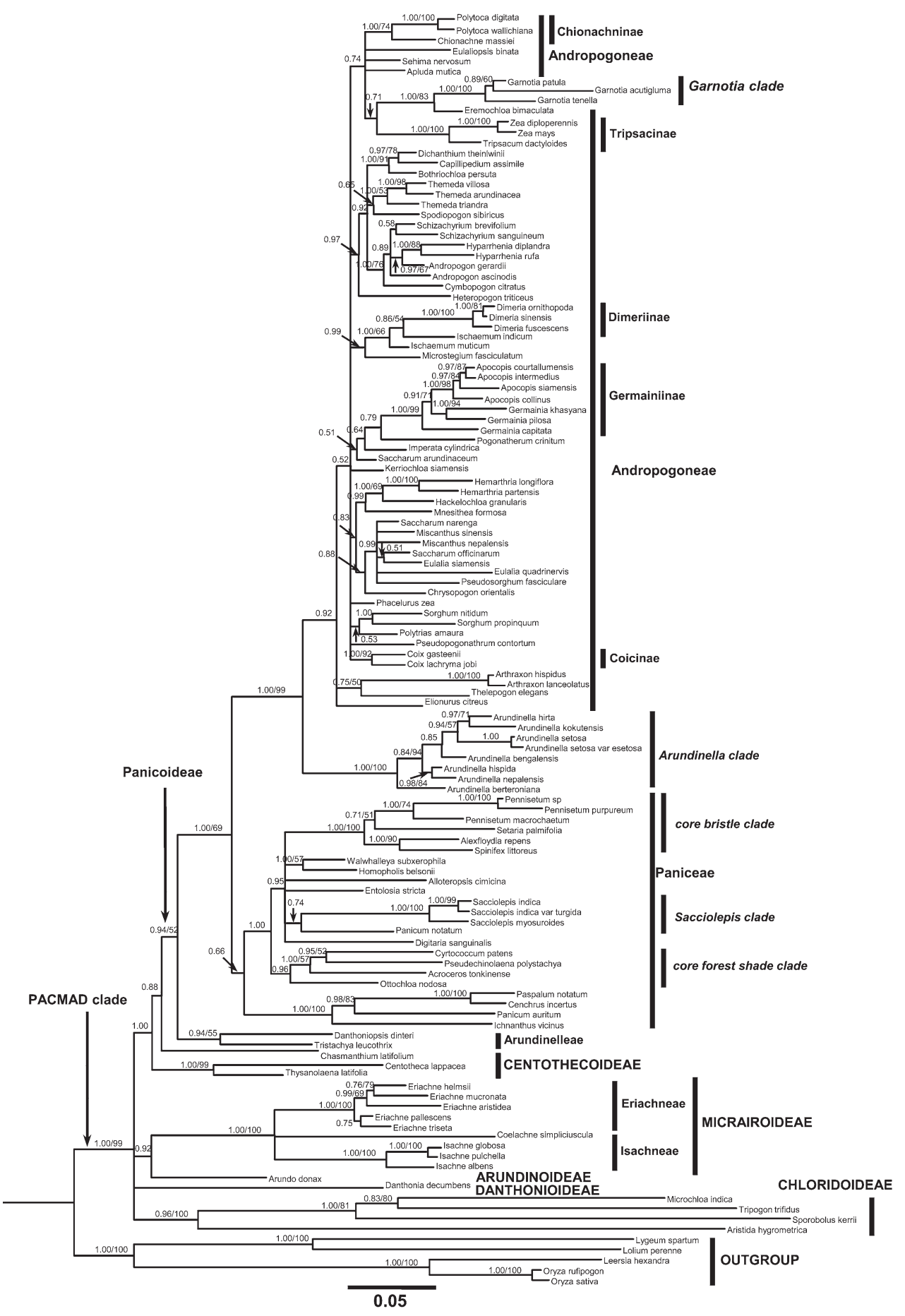

Fig. 1. Bayesian consensus tree from the combined analysis $(\operatorname{trn} \mathrm{L}-\mathrm{F}+a \operatorname{tp} \beta-r b c \mathrm{~L}+\mathrm{ITS})$ shown as a phylogram. Bayesian posterior probabilities and bootstrap values are shown above the branches. The PACMAD clade, and the subfamilial and the tribal classifications (the column on far right) are according to GPWG (2001) and Clayton and Renvoize (1986), respectively. 
$1.00 \mathrm{PP}$ ) and sister to Ottochloa (<50 BP, $0.96 \mathrm{PP}$ ). The clade consisting of Cenchrus, Ichnanthus, Panicum auritum and Paspalum was also resolved with high support (100 BP, $1.00 \mathrm{PP})$.

Andropogoneae and a Garnotia clade (100 BP, 1.00 PP) were grouped together with 0.92 PP. This clade was sister to an Arundinella clade (100 BP, 1.00 PP) with strong support (99 BP, 1.00 PP). Within Andropogoneae, five subtribes: Chionachninae, Coicinae, Dimeriinae, Germainiinae and Tripsacinae (according to Clayton \& Renvoize 1986), were monophyletic with 74, 92, 100, 99 and $100 \mathrm{BP}$, respectively (all with $1.00 \mathrm{PP}$ ). The relationships between the monophyletic subtribes and the rest of Andropogoneae were unclear, except Dimeriinae and Tripsacinae. Dimeriinae had Ischaemum indicum and I. muticum as its successively sister taxa with $54 \mathrm{BP}, 0.86 \mathrm{PP}$ and $66 \mathrm{BP}, 1.00 \mathrm{PP}$, respectively. Tripsacinae were sister to the clade consisting of Eremochloa and Garnotia (83 BP, 1.00 PP) with low support (<50 BP, $0.71 \mathrm{PP})$. Four out of a total of seven taxa from Rottboelliinae (Hackelochloa, Hemarthria longiflora, H. partensis and Mnesithea) were grouped with $0.99 \mathrm{PP}$. The monophyly of Arthraxon was resolved (100 BP, 1.00 PP). This clade was united with Thelepogon (50 BP, $0.75 \mathrm{PP}$ ). The monophyletic Hyparrhenia (88 BP, $1.00 \mathrm{PP}$ ) was sister to Andropogon gerardii (67 BP, $0.97 \mathrm{PP}$ ). This clade was grouped together with Andropogon ascinodis, Cymbopogon, and Schizachyrium (76 BP, 1.00 PP). A clade consisting of Bothriochloa, Capillipedium and Dichanthium was resolved (91 BP, 1.00 PP). The analysis also resolved the monophyly of Themeda with $53 \mathrm{BP}$ and $1.00 \mathrm{PP}$.

\section{Discussion}

\section{PACMAD Clade}

It is clear that the PACMAD clade, including Panicoideae sensu stricto (excluding Isachneae, Eriachneae and Arundinelleae, but including Arundinella and Garnotia), Arundinoideae, Chloridoideae, Micrairoideae sensu Sánchez-Ken et al. (2007), Aristidoideae and Danthonioideae, is monophyletic. It is also robustly supported based on molecular data by previous studies (e.g., Giussani et al. 2001, GPWG 2001, Sánchez-Ken et al. 2007, Christin et al. 2008, Edwards \& Smith 2010). Not all of these studies included representatives of each of the PACMAD subfamilies, but in combination they consistently grouped these taxa together. All members of this clade also have several apparently synapomorphic morphological or anatomical characters, such as the presence of an elongated mesocotyl internode and the loss of the epiblast (GPWG 2001). Within the PACMAD clade, the relationships among the six subfamilies were largely unresolved. The representatives of subfamily Centothecoideae (Centotheca, Chasmanthium and Thysanolaena) did not form a monophyletic group. Only Centotheca and Thysanolaena were grouped together with high support (99 BP, 1.00 PP). This relationship was also found in the studies of Bouchenak-Khelladi et al. (2008) and Christin et al. (2008). The grouping of members of Centothecoideae with the monophyletic Panicoideae is consistent with previous studies (Sánchez-Ken \& Clark 2001, Sánchez-Ken \& Clark 2007, Bouchenak-Khelladi et al. 2008). We therefore prefer to use the acronym PACMAD instead of PACCMAD, following Duvall et al. (2007). Micrairoideae, including Eriachneae and Isachneae, were monophyletic with strong support (100 BP, 1.00 PP), a finding consistent with previous studies (Duvall et al. 2007, Sánchez-Ken et al. 2007). However, the position of Micrairoideae within the 
PACMAD clade was not clear. The monophyly of Micrairoideae sensu Sánchez-Ken et al. (2007) with Eriachneae, Isachneae and Micraireae, was not well supported $(<50$ $\mathrm{BP}$ ) in the ITS analysis (S2, supplementary information). We can deduce some patterns from the MP analyses of single DNA regions. A strict consensus tree of these would reveal: $((($ Eriachne + Isachne $)+$ Coelachne $)$ Micraira $)$.

The monophyly of Eriachne, as found in the previous study by Sánchez-Ken et al. (2007), was consistently resolved and well supported (100 BP, 1.00 PP). Clayton and Renvoize (1986) noted that Eriachneae, consisting of Eriachne and Pheidochloa, closely resembles Isachneae, in the number of fertile florets and in the induration of lemmas with inrolled margins, but differs in having awned lemmas and Kranz anatomy. Isachneae, represented by Coelachne and Isachne, were non-monophyletic due to the exclusion of Coelachne (Figs. 1, S1). However, the result supported Isachne as monophyletic (100 BP, 1.00 PP). Morphologically, Isachneae, including Coelachne, Heteranthoecia, Isachne, Limnopoa and Sphaerocaryum, are characterised by having two fertile disarticulating florets and by their non-Kranz anatomy. Clayton and Renvoize (1986) suggested that Isachneae were most likely to be derived from Panicum based upon close morphological similarities of spikelets between Isachne and Panicum sect. Verruculosa. However, these similarities were found to be homoplasies by Sánchez-Ken et al. (2007).

Panicoideae sensu stricto (excluding Isachneae, Eriachneae and Arundinelleae, but including Arundinella and Garnotia) were supported as monophyletic (69 BP, 1.00 PP). Within the Panicoideae only the ((Andropogoneae + Garnotia) + Arundinella) clade (99 $\mathrm{BP}, 1.00 \mathrm{PP}$ ) can be identified. This finding is inconsistent with some previous studies in which Panicoideae were made up of three major clades, comprising Andropogoneae, Paniceae $[\mathrm{x}=10$ ] and Paniceae [x=9] (e.g., Gomez-Martinez \& Culham 2000, Giussani et al. 2001, Aliscioni et al. 2003, Vicentini et al. 2008). The failure to retrieve this topology could be due to uneven sampling among the clades.

Unfortunately, no DNA samples from two small tribes (monotypic Hubbardieae and the two genera of Steyermarkochloeae) were available in this study. Based on morphological data, Hubbardia, which was distinguished by the absence of paleas, was apparently derived from Isachneae (Clayton \& Renvoize 1986) sharing similarities in spikelet structure, the disarticulation of the florets above the glumes and the $\mathrm{C}_{3}$ photosynthetic pathway. Steyermarkochloeae are comprised of two extraordinary genera, Steyermarkochloa and Arundoclaytonia. Based on leaf blade anatomy, Davidse and Ellis (1984) first suggested that Steyermarkochloa was similar to an arundinoid grass such as Gynerium (now placed within the Panicoideae + Centothecoideae clade, Sánchez-Ken \& Clark 2001), Arundo, Phragmites and Thysanolaena (now Centothecoideae, GPWG, 2001). However, it was later transferred to be under Panicoideae because Steyermarkochloa is morphologically distinct from arundinoid grasses in almost all characters of leaves, inflorescences, spikelets and flowers (Clayton \& Renvoize 1986). Although Arundoclaytonia showed no anatomical resemblance with the panicoid grasses, it was included in Steyermarkochloeae on the basis of spikelet morphology (Davidse \& Ellis 1987). Recent phylogenetic study showed that Arundoclaytonia was grouped outside the Panicoideae clade. It was placed as sister to the PACMAD clade (Sánchez-Ken \& Clark 2007). 


\section{Tribes of Panicoideae}

\section{Paniceae}

A clade, consisting of Alexfloydia and three bristle clade taxa (Pennisetum, Setaria and Spinifex) was found to be monophyletic with high support (100 BS, 1.00 PP). Interestingly, Alexfloydia, a rare Australian grass, was placed in the bristle clade. It is a non bristle-bearing genus not included in any previous analyses. Some previous studies have also found non-bristle bearing taxa in the bristle clade (Gomez-Martinez \& Culham 2000, Giussani et al. 2001, Aliscioni et al. 2003, Bess et al. 2005, Doust et al. 2007; O. Morrone, Instituto de Botánica Darwinion, Argentina, 'pers. comm.'). Surprisingly, one of the bristle-bearing genera, Cenchrus (represented by a single taxon, C. incertus), was not grouped within this clade but was positioned within the clade that corresponds to $\mathrm{x}=10$ Paniceae, represented in this study by Ichnanthus, Paspalum and Panicum auritum, with high support (100 BP, 1.00 PP). Other Cenchrus species were previously placed in the bristle-clade of the $\mathrm{x}=9$ Paniceae (Doust et al. 2007, Christin et al. 2008, Vicentini et al. 2008), which suggests that this genus may be polyphyletic, but future studies are needed to test this hypothesis. Within the bristle clade, Pennisetum was monophyletic (74 BP, 1.00 PP). However, previous studies have found that Pennisetum was paraphyletic and always forms a monophyletic assemblage with Cenchrus (Giussani et al. 2001, Doust \& Kellogg, 2002, Doust et al. 2007, Donadio et al. 2009).

The forest shade clade, as defined by Giussani et al. (2001), was also resolved in this study (0.96 PP) with Acroceras, Ottochloa, Pseudechinolaena and a new member, Cyrtococcum. However, the monophyly of the forest shade clade, which was supported in other recent studies (Christin et al. 2008, Ibrahim et al. 2009), remained only moderately supported and ambiguous in our analyses (Figs 1, S1 \& S2).

Homopholis and Walwhalleya, endemic grasses from Queensland, Australia, were grouped together (57 BP, 1.00 PP). This grouping is inconsistent with the morphological phylogenetic trees of Wills et al. (2000) in which three members of Walwhalleya formed a monophyletic group and were sister to the clade consisting of Digitaria and Panicum, while Homopholis was well-supported as the most outlying member of the ingroup. The monotypic and endangered genus Homopholis was previously placed within section Digitariastrae under Paniceae, and considered to be closely related to Digitaria, but differing in its well developed lower glumes and comparatively small fertile florets (Clayton \& Renvoize 1986). However, this relationship was not supported by either the morphological study of Wills et al. (2000) or by the present molecular data although the topology here was only weakly supported.

Sacciolepis was also resolved as monophyletic with high support (100 BP, 1.00 PP), but its position was uncertain. Previously, Sacciolepis, represented by S. indica, was nested within the clade consisting of Panicum section Monticola, clade-Parvifolia clade-Verrucosa (Aliscioni et al.2003, Vicentini et al. 2008). Aliscioni et al. (2003) also suggested that the inclusion of Sacciolepis within this Panicum clade was doubtful because no apparent morphological relationship exists between Sacciolepis and those sections or groups. Sacciolepis comprising of c. 30 species is widely distributed in the tropics, especially in Africa. It is a distinctive genus and differs from the rest of Paniceae by the presence of spiciform panicle, with ribbed glumes and gibbous upper glumes (Clayton \& Renvoize 1986). 


\section{Arundinelleae}

Arundinelleae were polyphyletic and split into three clades: (1) an Arundinella clade (100 BP, 1.00 PP), which was sister to Andropogoneae, (2) a Garnotia clade (100 BP, $1.00 \mathrm{PP}$ ), which was embedded within Andropogoneae as sister to Tripsacinae (99 BP, $1.00 \mathrm{PP}$ ), and (3) a clade of Danthoniopsis + Tristachya (55 BP, $0.94 \mathrm{PP}$ ), which was sister to Panicoideae (52 BP, $0.94 \mathrm{PP}$ ). The grouping of Danthoniopsis and Tristachya was consistent with Sánchez-Ken et al. (2007), while the sister group relationship between Danthoniopsis + Tristachya clade and the panicoid clade can be interpreted as a novel result. However, this finding should be interpreted with care because some species of Tristachya have been placed within the Andropogoneae with high support (e.g., Hilu et al. 1999, Bouchenak-Khelladi et al. 2008).

Based on morphological characters, Arundinelleae taxa have the unique feature of the two-flowered spikelet with male or sterile lower floret and a bisexual upper floret. However, Arundinelleae differ from other panicoids in having a spikelet with a persistent glume (except Garnotia) (Clayton \& Renvoize 1986, Renvoize \& Clayton 1992). The non-monophyly of Arundinelleae has been reported in other phylogenetic analyses (e.g., Barker et al. 1999, Hilu et al. 1999, Spangler et al. 1999, GPWG 2001, Sánchez-Ken \& Clark 2007, Sánchez-Ken et al. 2007, Bouchenak-Khelladi et al. 2008). Therefore, the unique Arundinelleae sensu lato. morphological characters are most likely homoplasious. The classification at the generic level of Arundinelleae sensu lato is complex (Phipps 1966, Clayton \& Renvoize 1986) but, on the basis of anatomy, its taxa can be divided into two types, the non-Kranz type or $\mathrm{C}_{3}$ pathway in Chandrasekharania and Jansenella and the Kranz MS type or $\mathrm{C}_{4}$ pathway in the rest of the tribe (Clayton \& Renvoize 1986). It would be interesting to include those two genera in further analysis, especially Jansenella which was found as a morphologically intermediate taxon between Arundinella and Danthoniopsis (Bor 1955, Clayton \& Renvoize 1986, Teerawatananon \& Hodkinson 2008).

\section{Arundinella and Garnotia}

The results from the combined dataset supported the separation of Arundinella and Garnotia from the remaining Arundinelleae, and suggested that Arundinella and Garnotia could better be placed in their own subtribes (Arundinellinae Honda sensu stricto and Garnotiinae Pilger) within Andropogoneae and that Arundinelleae sensu lato should be abandoned as a taxonomic group. Although the appearance of Garnotia within Andropogoneae was previously demonstrated by the cluster analysis of Hilu and Wright (1982), the inclusion of Garnotia in Andropogoneae is a novel result overlooked by previous phylogenetic studies (e.g., Barker et al. 1999, Hilu et al. 1999, Spangler et al. 1999, GPWG 2001, Sánchez-Ken \& Clark 2007, Sánchez-Ken et al. 2007, Bouchenak-Khelladi et al. 2008) probably due to lack of Garnotia DNA samples. Arundinella was sister to Andropogoneae + Garnotia (99 BP, 1.00 PP). However, the position of Garnotia within Andropogoneae, relative to other subtribes was unclear. The Garnotia clade was found to be sister to Eremochloa ( $83 \mathrm{BP}, 1.00 \mathrm{PP}$ ) but there is no obvious shared morphology. Morphologically, Arundinella differs from the rest of Arundinelleae in having a membranous ligule, a scabrid upper lemma and a punctiform hilum, while Garnotia is distinguished by its single-flowered spikelets that disarticulate below the glumes (Clayton \& Renvoize 1986). Both genera differ from the rest of the tribe by having a punctiform hilum and a membranous ligule (Clayton \& Renvoize 1986). Anatomically, Arundinella and Garnotia are $C_{4}$ taxa but have isolated vascular 
bundle sheath cells (which were called distinctive cells or auxillary bundle cells), and auriculate paleas (Tateoka 1958, Clayton \& Renvoize 1986, Renvoize \& Clayton 1992). On the basis of our results these shared characters are homoplasious as Arundinella and Garnotia were not grouped together.

\section{Andropogoneae and its subtribal classification}

Andropogoneae were found to be monophyletic only if Garnotia was included ( $<50 \mathrm{BP}$, $0.92 \mathrm{PP}$ ) and this clade was united with Arundinella (99 BP, 1.00 PP) (Fig. 1). Within the tribe, none of the phylogenetic trees were consistent with the awned/awnless classification proposed by Clayton $(1972,1973)$. This hypothesis was supported by the molecular study of Mathews et al. (2002), but no strong evidence for this clade was found. It is clear that the subtribal classification of Clayton and Renvoize (1986) requires considerable revision (Kellogg 2000, Mathews et al. 2002) even though some subtribes (Chionachninae, Coicinae, Dimeriinae, Germainiinae and Tripsacinae) were supported as monophyletic in our study.

\section{Chionachninae, Coicinae and Tripsacinae}

All monoecious taxa of Andropogoneae were traditionally placed in Maydeae (Bentham 1882, Hackel 1889, Watson \& Dallwitz 1992 onwards, Kellogg \& Watson 1993). However, Maydeae were divided into three subtribes, Chionachninae, Coicinae and Tripsacinae by Clayton (1973) and Clayton and Renvoize (1986) using the difference of inflorescences and spikelets based mainly on the different origin of the bead-like feature of female spikelets (Clayton \& Renvoize 1986). In Chionachninae this structure is formed by a lower glume, while in Coicinae it is modified from a spatheole. These two subtribes completely differ from Tripsacinae in having paired female spikelets and the inflorescence rachis is broader than their spikelets.

In this study, Chionachninae, represented by Chionachne massiei, Polytoca digitata and P. wallichiana, were supported as monophyletic (74 BP, 1.00 PP). Polytoca wallichiana was first proposed under the name Cyathorhachis wallichiana by Steudel (1854). It was transferred to be Polytoca by Bentham (1882). Recently, the name Cyathorhachis was reinstated by Jannink and Veldkamp (2002). However, P. digitata and P. wallichiana are morphologically similar in many respects. The low level of genetic divergence between these two taxa also confirmed that $P$. wallichiana should be placed within Polytoca rather than Cyathorhachis. Morphologically, Chionachninae were found to be polyphyletic by Kellogg and Watson (1993) in which Polytoca was grouped together with Tripsacinae, while Chionachne was placed outside this clade. Clayton and Renvoize (1986) and Renvoize and Clayton (1992) suggested that Chionachninae are linked to Rottboelliinae by the appearance of the peg and the socket callus joints of sessile spikelets. This relationship was not supported by this study.

The monophyly of Coix (Coicinae) was demonstrated by Bomblies and Doebley (2005) and was also resolved with high support by this study (92 BP, 1.00 PP) as the Australian C. gasteenii grouped with the widespread C. lacryma-jobi. Morphologically, the highly modified inflorescence of the monotypic Coicinae is composed of paired unisexual racemes. Female racemes are hidden in an indurated utricle which is derived from a spatheole. These extraordinary modifications confirmed the separation of Coicinae from the remaining monoecious taxa and indicated a possible link with Apluda and Coicinae (Clayton \& Renvoize 1986, Renvoize \& Clayton 1992). However, this debate remains unresolved based on molecular data. 
Our study strongly supported the monophyly of Tripsacinae (100 BP, 1.00 PP). Species of this subtribe - Zea mays and wild species of Zea and Tripsacum - were grouped together (Clayton 1973, Clayton \& Renvoize 1986, Watson \& Dallwitz 1992 onwards, Kellogg 2000). Tripsacinae were also found to be monophyletic and closely related to Rottboelliinae and Chionachninae in all molecular studies to date (e.g., Spangler et al. 1999, Mathews et al. 2002, Bomblies \& Doebley 2005). A sister-group relationship between Tripsacinae and Rottboelliinae was not found in our study, but our combined dataset showed that Tripsacinae were grouped together with the clade consisting of Garnotia clade + Eremochloa with low support $(<50 \mathrm{BP}, 0.71 \mathrm{PP})$. There is no obvious morphological character to arrange these taxa together.

\section{Germainiinae}

Germainiinae, represented by Apocopis and Germainia, were highly supported (99 $\mathrm{BP}, 1.00 \mathrm{PP})$. These taxa have not been combined in phylogenetic analyses before. This novel clade is incongruent with the morphological phylogenetic trees of Kellogg and Watson (1993). Within Germainiinae, Apocopis was monophyletic (98 BP, 1.00 $\mathrm{PP}$ ). The taxa with awned upper lemmas (A. courtallumensis, A. intermedius and $A$. siamensis) form a clade with moderate support ( $84 \mathrm{BP}, 0.97 \mathrm{PP})$ and have the awnless upper lemma taxon (A. collinus) is the most outlying species to the rest of Apocopis. However, the monophyly of Apocopis was not supported by the combined chloroplast tree due to the inclusion of G. lanipes (Appendix 2, Fig. S1). Germainia was consistently paraphyletic in all analyses. Both MP and BI analyses found that G. khasyana was sister to G. pilosa (94 BP, 1.00 PP), while G. capitata was the next most outlying branch to the rest of Germainiinae.

\section{Dimeriinae}

The monotypic Dimeriinae (Dimeria spp.) was strongly supported (100 BP, 1.00 PP). A sister group relationship between Dimeriinae and Ischaeminae was demonstrated by the combined dataset in which Ischaemum indicum and I. muticum were successively sister taxa to a Dimeriinae clade. These relationships are inconsistent with the studies of Clayton and Renvoize (1986) and Kellogg and Watson (1993). Morphologically, Dimeriinae is unlike the remaining Andropogoneae in having a single pedicelled spikelet with no trace of the pairing (Clayton 1972) and hence it is presumably derived from that state (Renvoize \& Clayton 1992). According to Clayton and Renvoize (1986), Dimeriinae is linked to Pogonachne in the Ischaeminae through D. leptorhachis but differs by its espatheate inflorescences, racemes with tough rachis, epaleate florets and the presence of two stamens.

\section{Hackelochloa, Hemarthria and Mnesithea}

Although Rottboelliinae (with Elionurus, Eremochloa, Hackelochloa, Hemarthria, Mnesithea and Phacelurus) were not found to be monophyletic in this study, three genera, Hackelochloa, Hemarthria and Mnesithea, often grouped together, ( $<50 \mathrm{BP}, 0.99 \mathrm{PP})$. The monophyly of Hemarthria was confirmed by the combined dataset (100 BP, 1.00 PP). This clade was found to be closely related to Hackelochloa (69 BP, $1.00 \mathrm{PP})$. However, no obvious morphological traits support this relationship. The relationship between Hemarthria and Hackelochloa is inconsistent with the morphological studies of Clayton and Renvoize (1986) and Kellogg and Watson (1993). Morphologically, both genera are placed in Rottboelliinae based on the 
characters of awnless upper lemmas, thickened internodes and the fused pedicel to internode (Clayton 1973). Hemarthria can be distinguished from the rest of its subtribe in possessing tough rachis and an oblique basal callus, while Hackelochloa is the only genus in the subtribe having globose sessile spikelets with wingless lower glumes (Clayton \& Renvoize 1986).

\section{Bothriochloa, Capillipedium and Dichanthium}

Three genera, Bothriochloa, Capillipedium and Dichanthium, were found to form a monophyletic group in the combined analysis (91 BP, $1.00 \mathrm{PP})$ and this clade has also been resolved by previous molecular studies (e.g., Spangler et al. 1999, Mathews et al. 2002, Skendzic et al. 2007). These three genera are known as an agamic complex and have produced a large number of interspecific and some intergeneric hybrids (Harlan \& De Wet 1963, De Wet \& Harlan 1970). However, this relationship was not supported by most morphological studies of Clayton and Renvoize (1986), Watson and Dallwitz (1992 onwards) and Kellogg and Watson (1993) and most studies preferred to keep these three genera separate. Morphologically, Dichanthium is closely related to Bothriochloa in having sub-digitate racemes, but can be distinguished by its pedicels and rachis internodes being solid and lacking a translucent median line. The members of Capillipedium are often confused with members of Bothriochloa, but the former differs in having paniculate inflorescences and short racemes often reduced to triads (Clayton \& Renvoize 1986). Based on molecular data, this clade was previously found to be within the core Andropogoneae (Spangler et al. 1999, Mathews et al. 2002, Skendzic et al. 2007). This relationship was also resolved in this study. The core Andropogoneae (with Andropogon, Coix, Cymbopogon, Heteropogon, Hyparrhenia, Schizachyrium and Sorghastrum) was informally named by Spangler et al. (1999) corresponding to the chromosome number $(x)$ of 20 . The core Andropogoneae was later found to be non-monophyletic by Mathews et al. (2002) and Skendzic et al. (2007) due to the exclusion of Coix.

\section{Other genera and unresolved topology}

The results from all analyses confirmed the monophyly of Arthraxon (100 BP, 1.00 PP). Morphologically, Arthraxon is distinguished from all other Andropogoneae by its lemmas with a sub-basal awn.

Hyparrhenia was resolved as monophyletic (88 BP, $1.00 \mathrm{PP}$ ). Clayton and Renvoize (1986) suggested that Hyparrhenia is closely related to Andropogon and Cymbopogon. This study also found that a Hyparrhenia clade was sister to Andropogon gerardii (67 BP, 0.97 PP). This clade was grouped together with three other taxa, Cymbopogon, Schizachyrium and Andropogon ascinodis (76 BP, $1.00 \mathrm{PP})$. Themeda was also monophyletic (53 BP, 1.00 PP). Morphologically, Themeda is distinctive among the sampled Anthistiriinae in that its racemes have two large homogamous pairs at the base and upper lemmas are entire. According to Clayton and Renvoize (1986), the position of Themeda within Anthistiriinae should be between Heteropogon and Iseilema. The relationship between Iseilema and Themeda was also found in the study of Kellogg and Watson (1993). However, none of our analyses supported this hypothesis.

Although several well supported groups have been identified, the present matrix with three non-coding markers ( $\operatorname{trn} \mathrm{L}-\mathrm{F}$, atp $\beta-r b c \mathrm{~L}$ and ITS) was insufficient to provide enough phylogenetic informative characters to resolve many evolutionary relationships at the intergeneric level in Andropogoneae. There are several reports 
of phylogenetic analyses within the angiosperms that have encountered similar difficulties with resolution due to short lengths of internal branches relative to terminal branches (e.g., Kellogg 2000, Mathews et al. 2002, Wortley et al. 2005). These patterns have been explained by suggesting that the groups have undergone rapid phylogenetic radiation (and that the phylogenetic signal to resolve the inter-relationships of the lineages has been lost). However, the theory behind such empirical observations and deductions is not well developed or reported (Moore et al. 2007). Adding more data and more taxa are the only ways of resolving these difficult groups (Hillis et al. 2003, Hodkinson et al. 2007a, Pirie et al. 2008). Choice of gene is also critical and it would be worthwhile sequencing a large number of more slowly evolving genes to reconstruct the phylogenetic patterns inside these clades of Panicoideae (Hodkinson et al. 2007a, Moore et al. 2007, Pirie et al. 2008).

\section{Conclusions and resulting taxonomy}

In this study, 42 out of 85 genera of Andropogoneae, representing 11 subtribes, were sampled and sequenced using three non-coding markers from both chloroplast and nuclear ribosomal DNA. We present our taxonomy of Arundinellinae and Garnotiinae:

Subtribe Arundinellinae Honda, J. Fac. Sci. Univ. Tokyo Bot. 3: 303. 1930. Type: Arundinella Raddi.

Arundinellinae as treated here includes only its type genus: Arundinella. This subtribe was first established with three genera: Arundinella, Phaenosperma and Thysanolaena (Honda, 1930). However, a recent systematic treatment of Poaceae placed Phaenosperma in Pooideae and grouped Thysanolaena within Centothecoideae (GPWG, 2001).

Subtribe Garnotiinae Pilger in Engl. \& Prantl, Nat. Pflanzenfam. Aufl. 14d: 167. 1956. Garnotiinae Pilger in Bot. Jahrb. 76(3): 341. 1954. nomen. Type: Garnotia Brongn.

Included genus: Garnotia.

\section{Acknowledgments}

Atchara Teerawatananon and Trevor Hodkinson would like to express their gratitude to friend and co-author Surrey Jacobs who died during the preparation of this manuscript. He commented on the results but sadly did not see the finished paper. He enthusiastically helped Trevor to collect Australian grass samples during his research sabbatical to Sydney Botanic Gardens in 2005. He then tirelessly continued collecting specimens for the project even when very sick. Due to his knowledge and efforts, we now have a much better understanding of Australian grasses and have added over 300 species to our collection for future systematic work. This work formed part of the PhD thesis of the first author and was supported by the TRF/BIOTEC Special Program for Biodiversity Research and Training Grant BRT_148026, the Trinity College Dublin Postgraduate Travel Reimbursement Fund, Natural History Museum, National Science Museum, Technopolis, Pathum Thani, Thailand. We wish to thank Dr Simon Laegaard, Dr Sarawood Sungkaew and Ms Narumon Kritsanachandee who helped collect grass specimens. We also thank Dr David Simpson, Stephen Renvoize, Dr Vincent Savolainen and Mr Laszlo Csiba for help in the herbarium and the Jodrell Laboratory of the Royal Botanic Gardens, Kew, England. Special thanks to Dr Nicolas Salamin for help with the Bayesian analysis. 


\section{References}

Aliscioni SS, Giussani LM, Zuloaga FO \& Kellogg EA (2003) A molecular phylogeny of Panicum (Poaceae: Paniceae): tests of monophyly and phylogenetic placement within the Panicoideae. American Journal of Botany 90: 796-821.

Baldwin BG, Sanderson M J, Porter JM, Wojciechowski MF, Campbell C \& Donoghue MJ (1995) The ITS region of nuclear ribosomal DNA: a valuable source of evidence on angiosperm phylogeny. Annals of the Missouri Botanical Gardens 82: 247-277.

Barker NP, Linder HP \& Harley EH (1999) Sequences of the grass-specific insert in the chloroplast rpoC2 gene elucidate generic relationships of the Arundinoideae (Poaceae). Systematic Botany 23: 327-350.

Bentham G (1882) Notes on Gramineae. The Journal of the Linnean Society 19: 14-134.

Bess EC, Doust AN \& Kellogg EA (2005) A naked grass in the "bristle clade": a phylogenetic and developmental study of Panicum section Bulbosa (Paniceae: Poaceae). International Journal of Plant Sciences 166: 371-381.

Bomblies K \& Doebley J (2005) Pleiotropic effects of the duplicate maize FLORICAULA/LEAFY genes $z f l$ and $z f l 2$ on traits under selection during maize domestication. Genetics 172: 519531.

Bor NL (1955) Notes on Asiatic grasses XXIII: Jansenella Bor, a new genus of Indian grasses. Kew Bulletin 1955: 93-99.

Bouchenak-Khelladi Y, Salamin N, Savolainen V, Forest F, van der Bank M, Chase MW \& Hodkinson TR (2008) Large multi-gene phylogenetic trees of the grasses (Poaceae): progress towards complete tribal and generic level sampling. Molecular Phylogenetics and Evolution 47: 488-505.

Chase MW \& Hills HH (1991) Silica gel: an ideal material for field preservation of leaf samples for DNA studies. Taxon 40: 215-220.

Christin P-A, Besnard G, Samaritani E, Duvall MR, Hodkinson TR, Savolainen V \& Salamin N (2008) Oligocene $\mathrm{CO}_{2}$ decline promoted $\mathrm{C}_{4}$ photosynthesis in grasses. Current Biology 18:37-43.

Clayton WD (1972) The awned genera of Andropogoneae: studies in the Gramineae XXXI. Kew Bulletin 27: 457-474.

Clayton WD (1973) Studies in the Gramineae XXXIII: the awnless genera of Andropogoneae. Kew Bulletin 28: 49-58.

Clayton WD \& Renvoize SA (1986) Genera Graminum. Grasses of the world. Kew Bulletin, Additional Series 13: 1-389.

Davidse G \& Ellis RP (1984) Steyermarkochloa unifolia, a new genus from Venezuela and Columbia (Poaceae: Arundinoideae: Steyermarkochloeae). Annals of the Missouri Botanical Garden 71: 994-1012.

Davidse G \& Ellis RP (1987) Arundoclaytonia, a new genus of Steyermarkochloeae (Poaceae: Arundinoideae) from Brazil. Annals of the Missouri Botanical Garden 74: 479-490.

De Wet JMJ \& Harlan JR (1966) Morphology of the compilospecies Bothriochloa intermedia. American Journal of Botany 53: 94-98.

De Wet JMJ \& Harlan JR (1970) Bothriochloa intermedia. A taxonomic dilemma. Taxon 19:339-340.

Donadio S, Giussani LM, Kellogg EA, Zuolaga FO \& Morrone O (2009) A preliminary molecular phylogeny of Pennisetum and Cenchrus (Poaceae-Paniceae) based on the trnL-F, rpl16 chloroplast markers. Taxon 58: 392-404.

Doust AN \& Kellogg EA (2002) Inflorescence diversification in the panicoid "bristle grass" clade (Paniceae, Poaceae): evidence from molecular phylogenies and developmental morphology. American Journal of Botany 89: 1203-1222.

Doust AN, Penly AM, Jacobs SWL \& Kellogg EA (2007) Congruence, conflict, and polyploidization shown by nuclear and chloroplast markers in the monophyletic "bristle clade" (Paniceae, Panicoideae, Poaceae). Systematic Botany 32: 531-544.

Doyle JJ \& Doyle JL (1987) A rapid DNA isolation procedure for small quantities of fresh leaf tissue. Phytochemical Bulletin for the Botany Society of America 19: 11-15. 
Duvall MR, Davis JI, Clark LG, Noll JD, Goldman DH \& Sánchez-Ken JG (2007) Phylogeny of the grasses (Poaceae) revisited. Aliso 23: 237-247.

Felsenstein J (1985) Confidence limits on phylogenies: an approach using the bootstrap. Evolution 39: 783-791.

Giussani LM, Cota-Sanches JH, Zuloaga FO \& Kellogg EA (2001) A molecular phylogeny of the grass subfamily Panicoideae (Poaceae) shows multiple origins of $\mathrm{C}_{4}$ photosynthesis. American Journal of Botany 88: 1993-2012.

Gomez-Martinez R \& Culham A (2000) Phylogeny of the subfamily Panicoideae with emphasis on the tribe Paniceae: evidence from the trnL-F chloroplast DNA region. Pp. 136-140 in Jacobs SWL \& Everett J (eds) Grasses: Systematics and Evolution. (Collingwood, Victoria: CSIRO Publishing)

GPWG (2001) Phylogeny and subfamily classification of the grasses (Poaceae). Annals of the Missouri Botanical Garden 88: 373-430.

Hackel E (1889) Andropogoneae. Pp. 1-716 in De Candolle A \& De Candolle C (eds) Monographiae Phanerogamarum, vol. 6.(Sumptibus G. Masson: Paris)

Harlan JR \& De Wet JMJ (1963) The compilospecies concept. Evolution 17: 497-501.

Hillis DM, Pollock DD, McGuire JA \& Zwickl DJ (2003) Is sparse taxon sampling a problem for phylogenetic inference? Systematic Biology 52: 124-126.

Hilu KW \& Wright K (1982) Systematics of Gramineae: a cluster analysis study. Taxon 31: 9-36.

Hilu KW, Alice LA \& Liang HP (1999) Phylogeny of Poaceae inferred from matK sequences. Annals of the Missouri Botanical Garden 86: 835-851.

Hodkinson TR, Salamin N, Chase MW, Bouchenak-Khelladi Y, Renvoize SA \& Savolainen V (2007a) Large trees, supertrees and diversification of the grass family. Aliso 23: 248-258.

Hodkinson TR, Waldren S, Parnell JAN, Kelleher CT, Salamin K \& Salamin N (2007b) DNA banking for plant breeding, biotechnology and biodiversity evaluation. Journal of Plant Research 120: 17-29.

Huelsenbeck JP \& Ronquist F (2001) MrBayes: Bayesian inference of phylogeny. Bioinformatics 17: 754-755.

Ibrahim DG, Burke T, Ripley BS \& Osborne CP (2009) A molecular phylogeny of the genus Alloteropsis (Panicoideae, Poaceae) suggests an evolutionary reversion from $\mathrm{C}_{4}$ to $\mathrm{C}_{3}$ photosynthesis. Annals of Botany 103: 127-136.

Jannink TA \& Veldkamp JF (2002) Revision of Chionachninae (Gramineae: Andropogoneae). Blumea 47: 545-580.

Kelchner SA (2000) The evolution of non-coding chloroplast DNA and its application in plant systematics. Annals of the Missouri Botanical Garden 87: 182-198.

Kellogg EA (2000) Molecular and morphological evolution in Andropogoneae. Pp. 149-158 in Jacobs SWL \& Everett J (eds) Grasses: Systematics and Evolution. (CSIRO Publishing: Collingwood)

Kellogg EA \& Campbell CS (1987) Phylogenetic nalyses of the Gramineae. Pp. 310-322 in Soderstrom TR, Hilu KW, Campbell CS \& Barkworth ME (eds) Grass Systematics and Evolution. (Smithsonian Press: Washington, D.C)

Kellogg EA \& Watson L (1993) Phylogenetic studies of a large dataset. I. Bambusoideae, Andropogonodae and Pooideae (Gramineae). Botanical Review 59: 273-343.

Mathews S, Spangler RE, Mason-Gamer RJ \& Kellogg EA (2002) Phylogeny of Andropogoneae inferred from phytochrome B, GBSSI and ndhF. International Journal of Plant Sciences 163: 441-450.

Moore MJ, Bell CD, Soltis PS \& Soltis DE (2007) Using plastid genomic-scale data to resolve enigmatic relationships among basal angiosperms. Proceedings of the National Academy of Sciences 104: 19363-19368.

Phipps JB (1966) Studies in the Arundinelleae III: check-list and key to the genera. Kirkia 5: $235-258$.

Pirie MD, Humphreys AM, Galley C, Barker NP, Verboom GA, Orlovich D, Draffin SJ, Lloyd K, Baeza CM, Negritto M, Ruiz E, Cota-Sánchez JH, Reimer E \& Linder HP (2008) A novel supermatrix approach improves resolution of phylogenetic relationships in a comprehensive sample of danthonioid grasses. Molecular Phylogenetics and Evolution 48: 1106-1119. 
Posada D \& Crandall KA (1998) Modeltest: testing the model of DNA substitution. Bioinformatics 49: 817-818.

Rambaut A (1996) Se-Al Sequence Alignment Editor, vers. 2.0a11. (University of Oxford: Oxford)

Reeves G, Chase MW, Goldblatt P, Rudall P, Fay MF, Cox AV, Lejeune B \& Souza-Chies T (2001) Molecular systematics of Iridaceae: evidence from four plastid DNA regions. American Journal of Botany 88: 2074-2087.

Renvoize SA \& Clayton WD (1992) Classification and evolution of grasses. Pp. 3-37 in Chapman GP (ed.) Grass Evolution and Domestication. (Cambridge University Press: Cambridge)

Samuel R, Pinsker W \& Kiehn M (1997) Phylogeny of some species of Cyrtandra (Gesneriaceae) inferred from the atp $\beta / r b c \mathrm{~L}$ cpDNA intergene region. Botanica Acta 110: 503-510.

Sánchez-Ken JG \& Clark LG (2001) Gynerieae: a new neotropical tribe of grasses (Poaceae). Novon 11: 350-352.

Sánchez-Ken JG, Clark LG, Kellogg EA \& Kay EE (2007) Reinstatement and emendation of subfamily Micrairoideae (Poaceae). Systematic Botany 32: 71-80.

Sánchez-Ken JG \& Clark LG (2007) Phylogenetic relationships within the Centothecoideae + Panicoideae clade (Poaceae) based on $n d h F$ and rpll6 sequences and structural data. Aliso 23: 487-502.

Skendzic EM, Columbus JT \& Cerros-Tlatilpa R (2007) Phylogenetics of Andropogoneae (Poaceae: Panicoideae) based on nuclear ribosomal internal transcribed spacer and chloroplast trnL-F sequences. Aliso 23: 530-544.

Spangler R, Zaitchick B, Russo E \& Kellogg EA (1999) Andropogoneae evolution and generic limits in Sorghum (Poaceae) using $n d h F$ sequences. Systematic Botany 24: 267-283.

Steudel EG (1854) Synopsis plantarum glumacearum, vol. 1. (J. B. Metzler: Stuttgart)

Sun Y, Skinner DZ, Liang GH, Hulbert SH (1994) Phylogenetic analysis of Sorghum and related taxa using internal transcribed spacers of nuclear ribosomal DNA. Theoretical and Applied Genetics 89: 26-32.

Swofford DL (2002) PAUP*. Phylogenetic Analysis Using Parsimony ( ${ }^{*}$ and Other Methods) vers. 4.0b10. (Sinauer Associates: Sunderland)

Taberlet P, Gielly L, Pautou G, Bouvet J (1991) Universal primers for amplification of three noncoding regions of chloroplast DNA. Plant Molecular Biology 17: 1105-1109.

Tateoka T (1958) Note on some grasses VIII: on leaf structure of Arundinella and Garnotia. Botanical Gazette 20: 101-109.

Tateoka T (1962) Starch grains of endosperm in grass systematics. Botanical Magazine, Tokyo 75: 377-383.

Teerawatananon A \& Hodkinson TR (2008) Jansenella griffithiana (Müll. Hal.) Bor (Gramineae/ Poaceae): a new record for Thailand. Thai Forest Bulletin (Botany) 36: 109-113.

Thomson JA (2002) An improved non-crogenic transport and storage preservative facilitating DNA extraction from 'difficult' plants collected at remote sites. Telopea 9: 755-760.

Vicentini A, Barber JC, Aliscioni AA, Giussani LM \& Kellogg EA (2008) The age of the grasses and clusters of origins of $\mathrm{C}_{4}$ photosynthesis. Global Change Biology 14: 2693-2977.

Watson L \& Dallwitz MJ (1992 onwards) The grass genera of the world: descriptions, illustrations, identification, and information retrieval; including synonyms, morphology, anatomy, physiology, phytochemistry, cytology, classification, pathogens, world and local distribution, and references. (http://delta-intkey.com) (Downloaded 02 March 2009).

Wills KE, Whalley RDB \& Bruhl JJ (2000) Systematic studies in Paniceae (Poaceae): Homopholis and Whalleya gen. et sp nov. Australian Systematic Botany 13: 437-468.

Wortley AH, Rudall PJ, Harris DJ \& Scotland RW (2005) How much data are needed to resolve a difficult phylogeny?: case study in Lamiales. Systematic Biology 54: 697-709. 


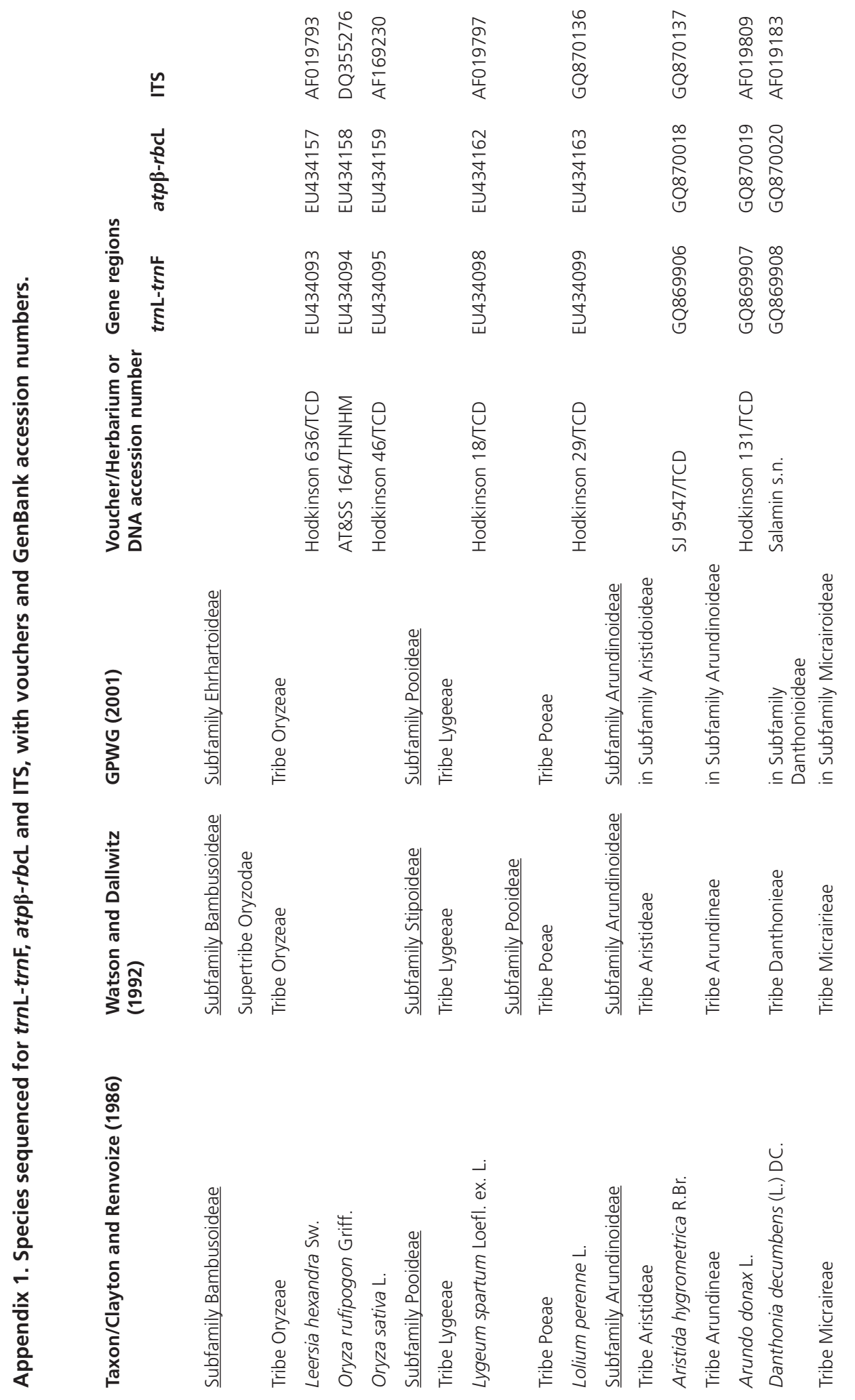




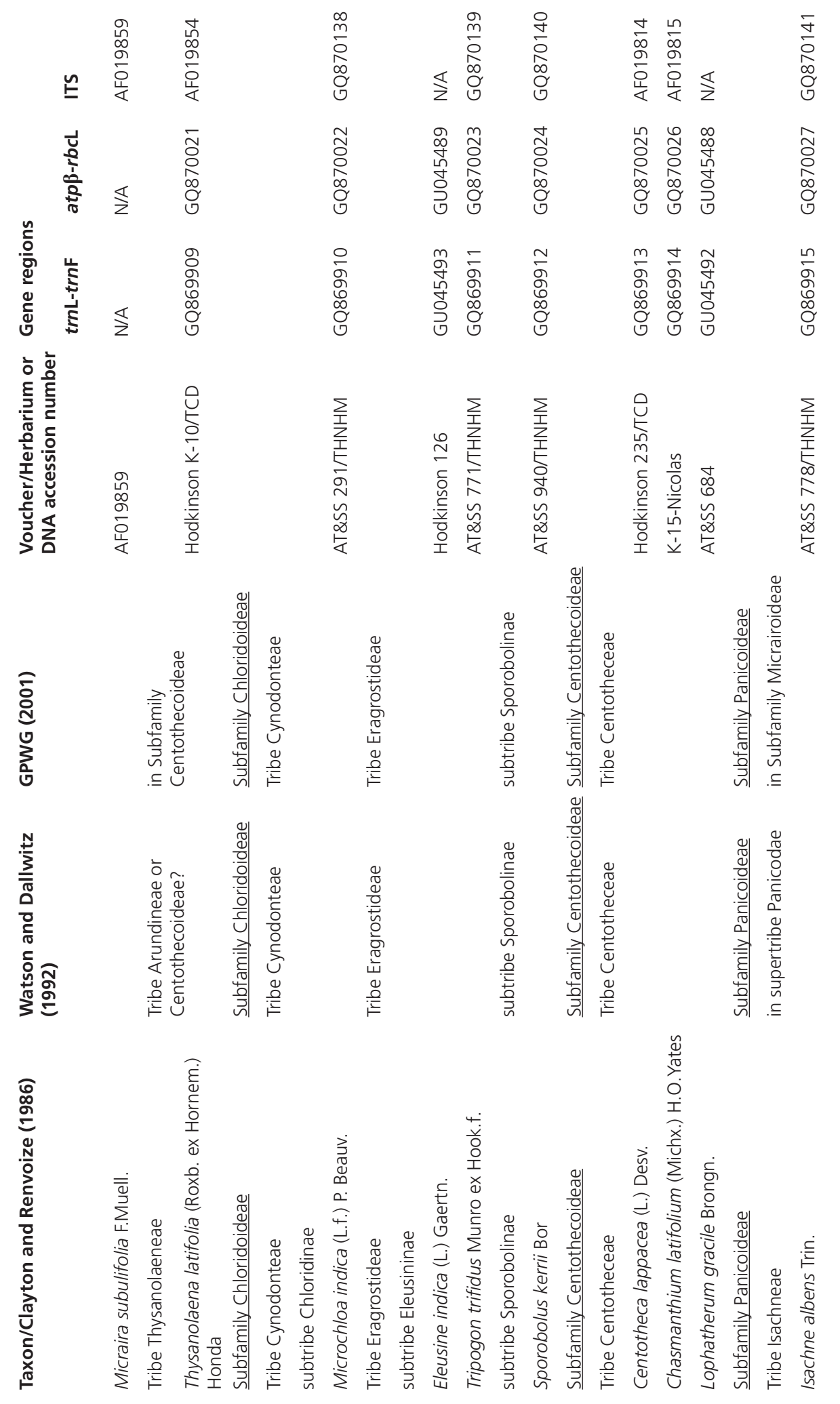




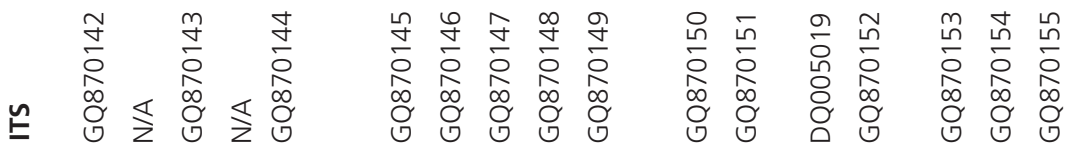

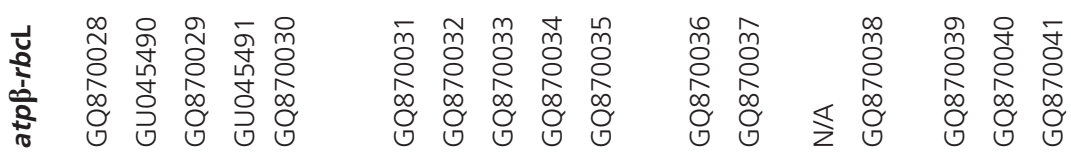

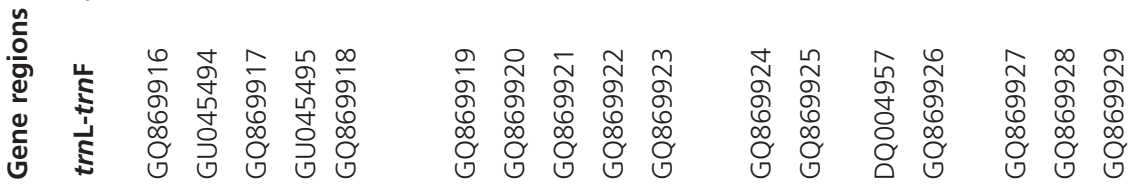

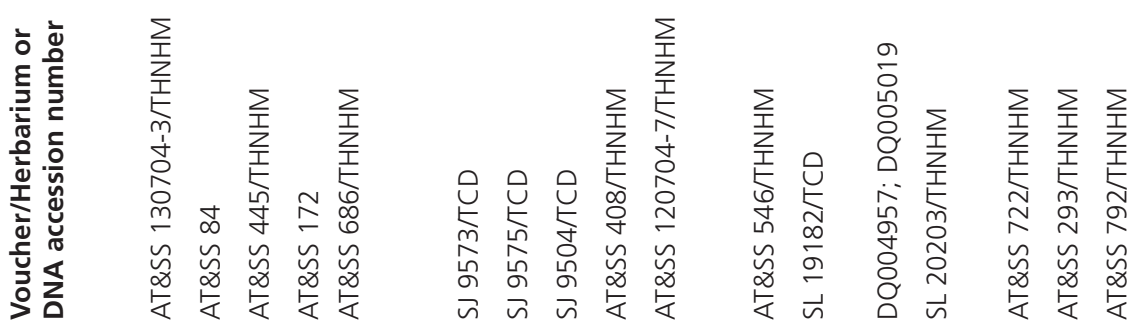

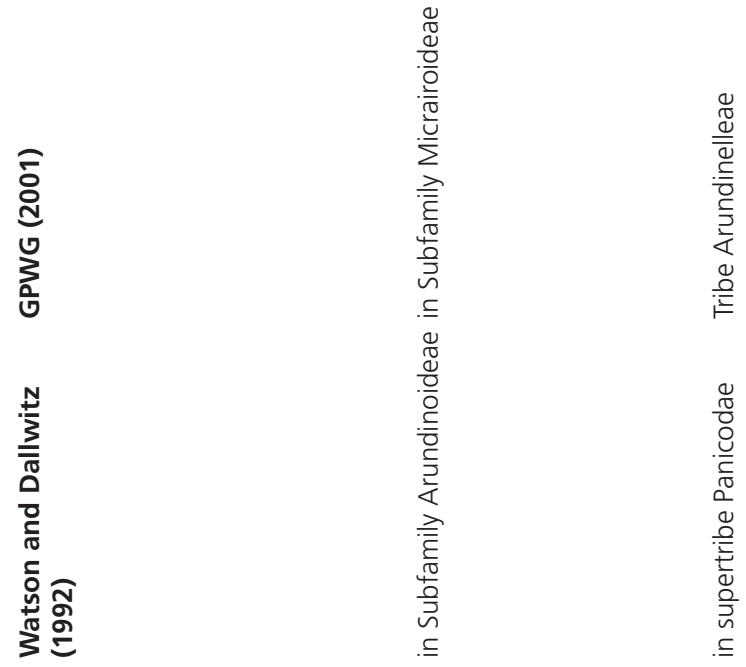

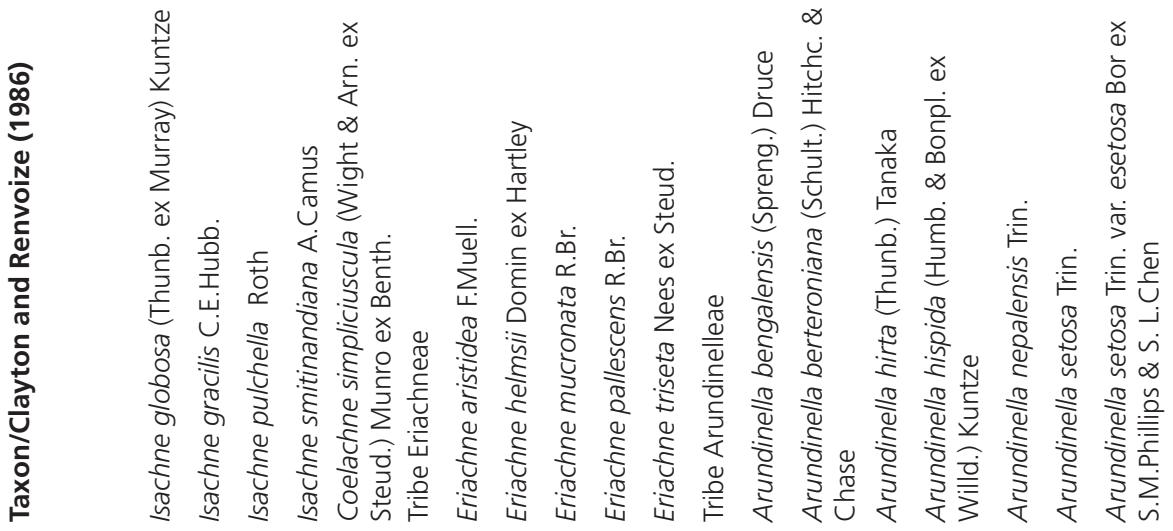




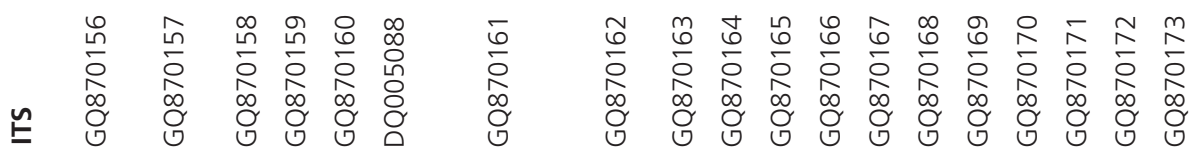

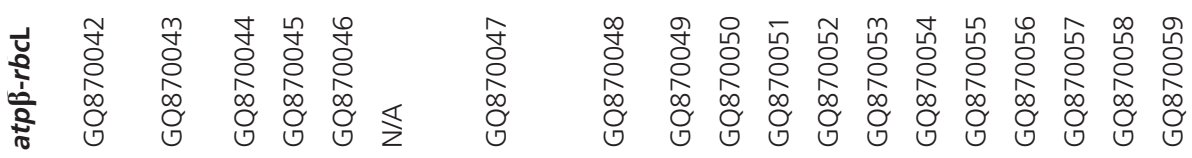

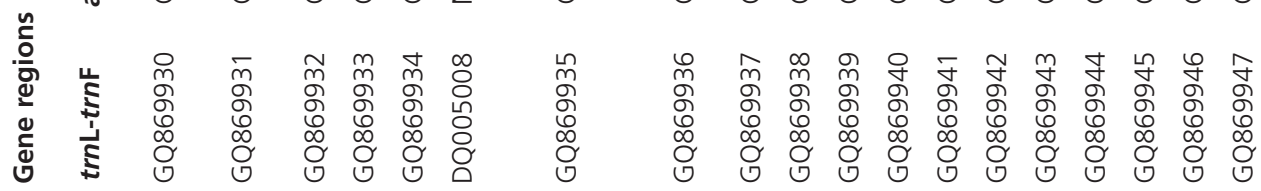
ᄒᄒ

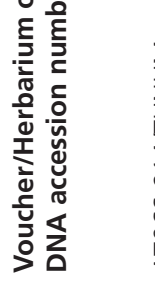
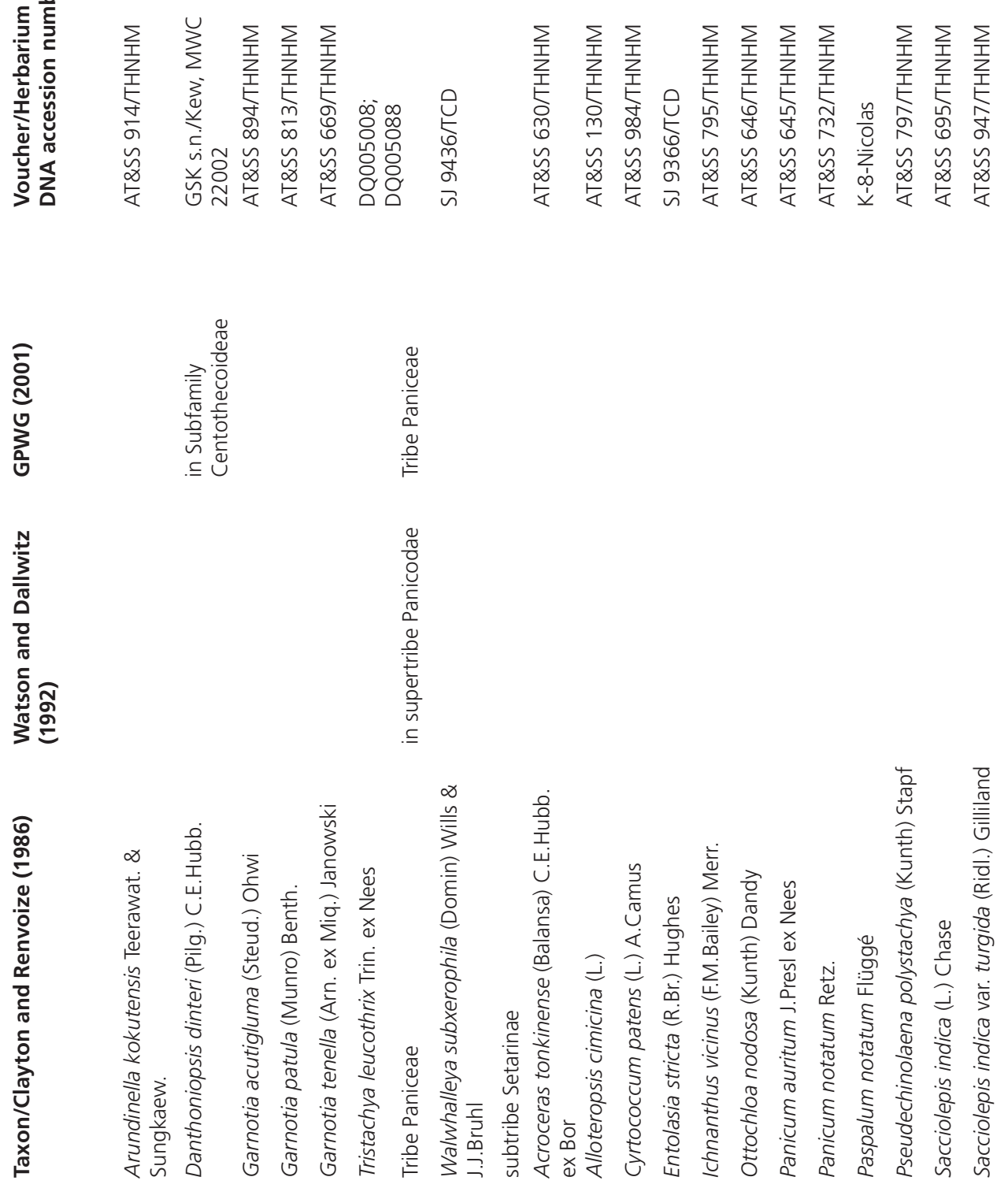


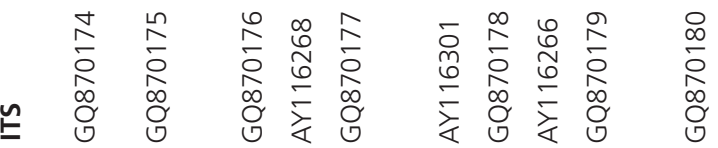

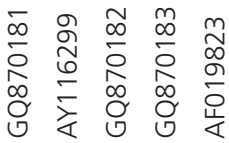

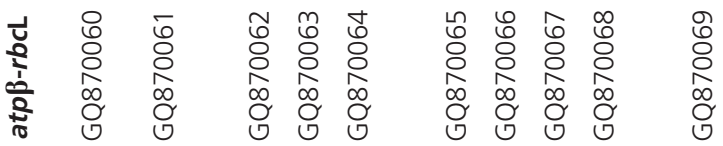

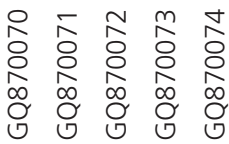

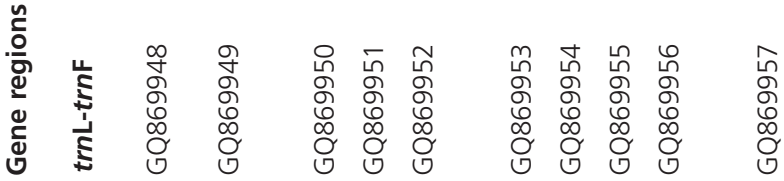

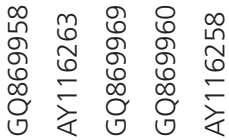

ᄒ̀ ळ

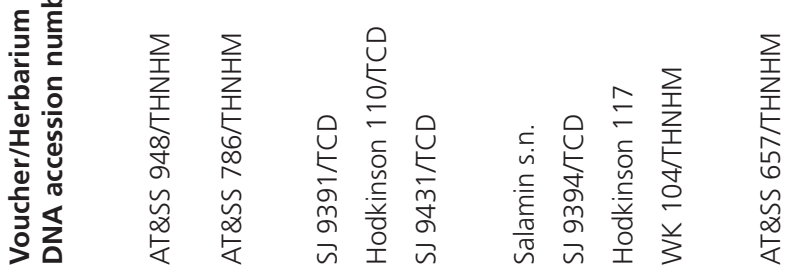

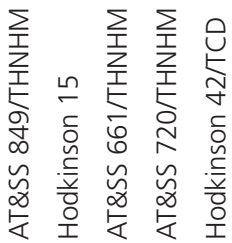

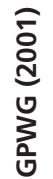

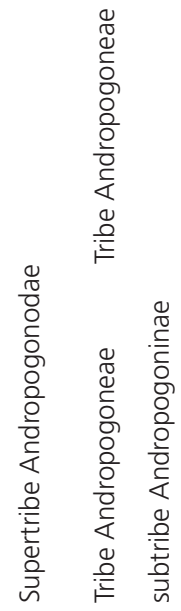

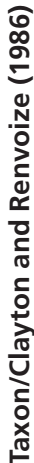
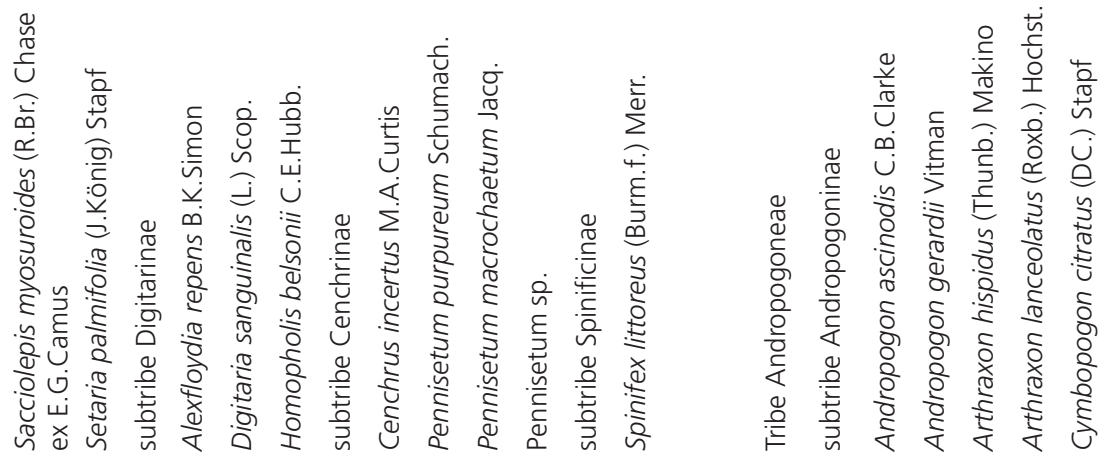


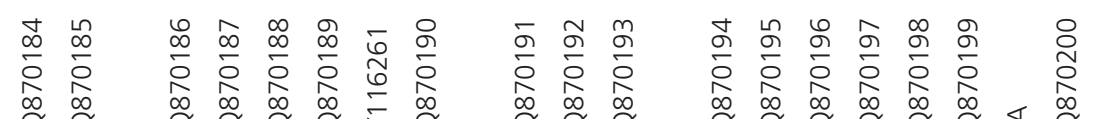

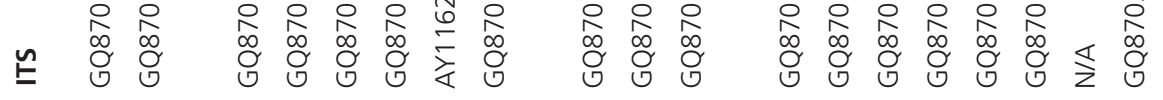

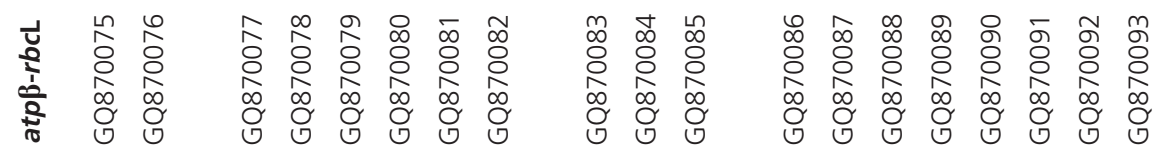

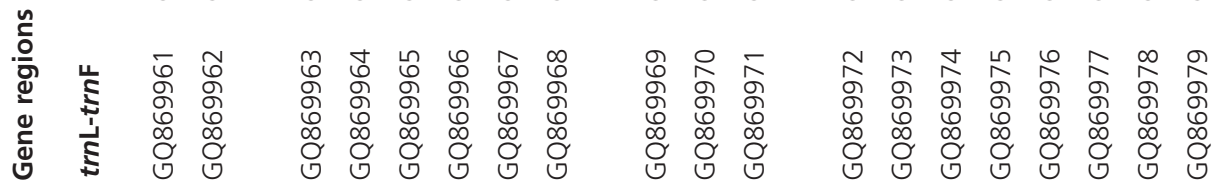
ᄒ̀ ऐั

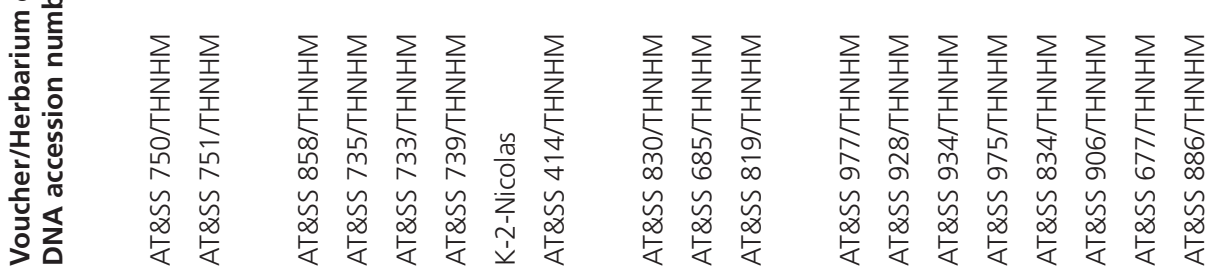

产

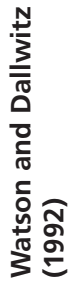

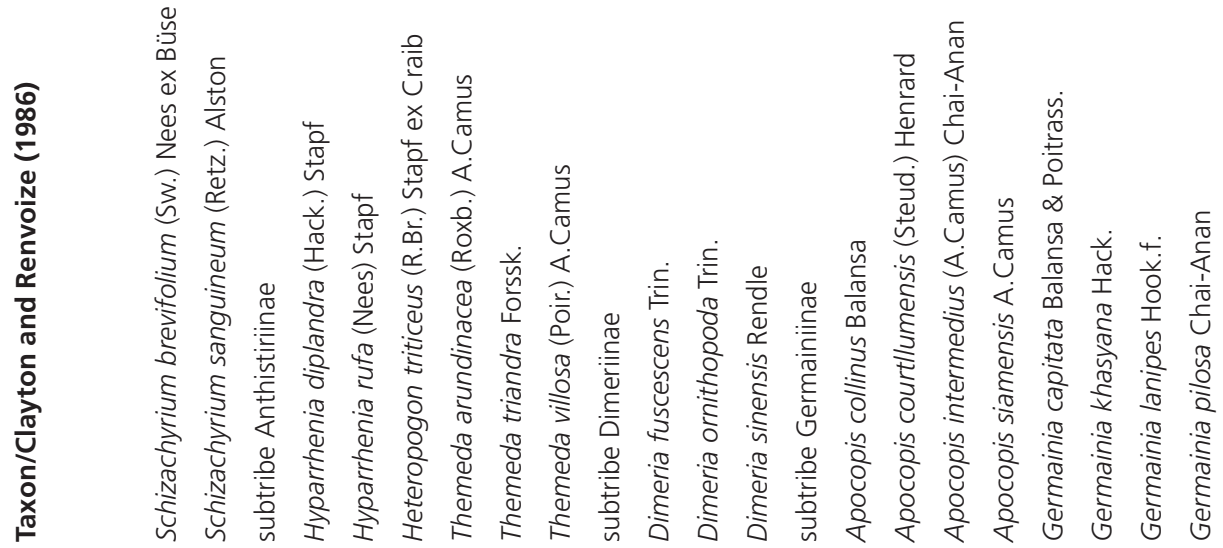




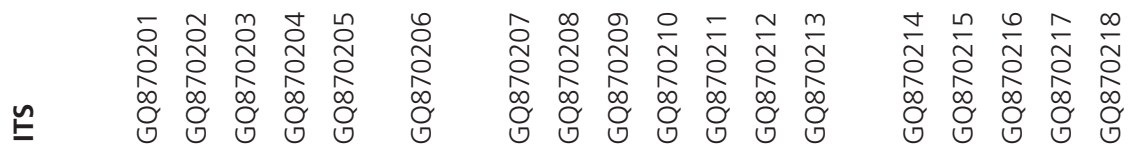

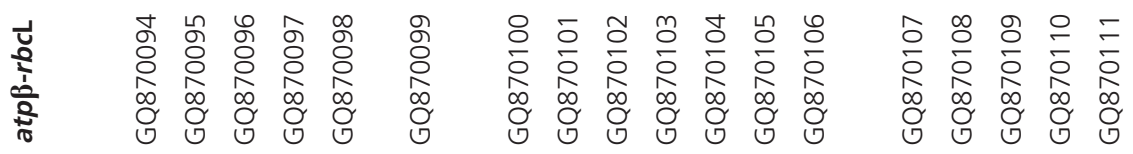

ᄂ.

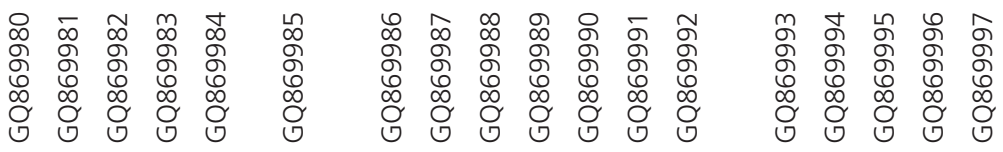

ㅎํ

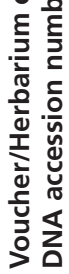

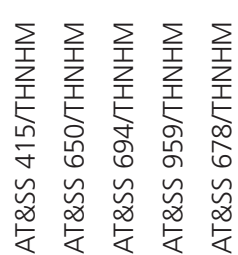

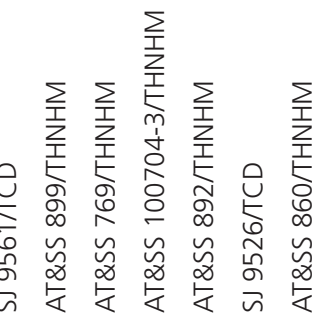

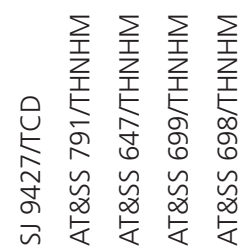

엉

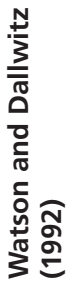

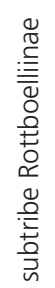

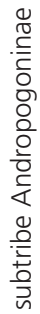

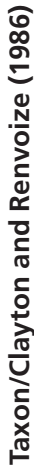

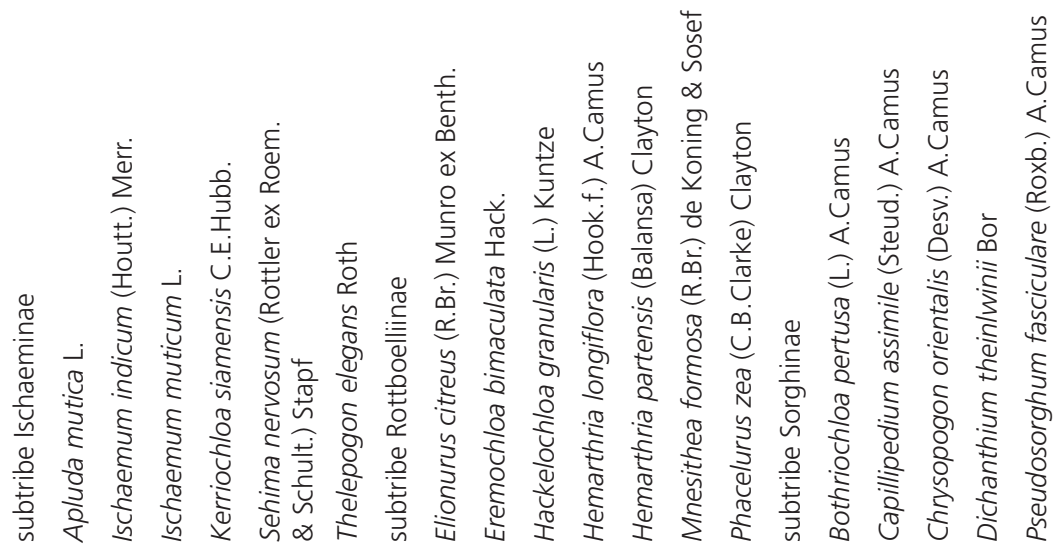




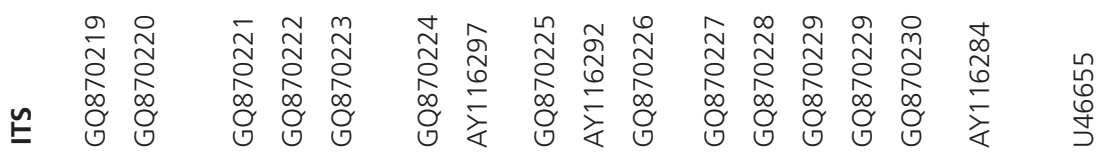

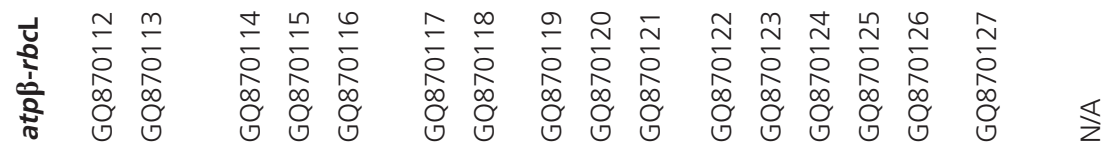

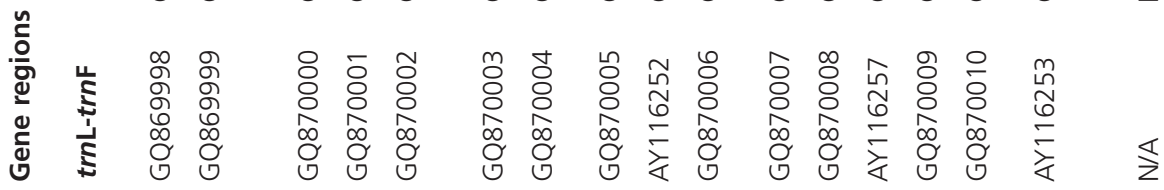

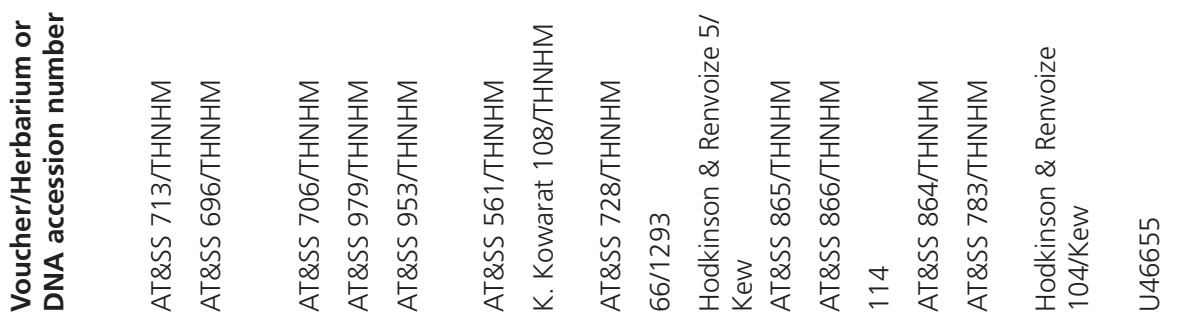

产

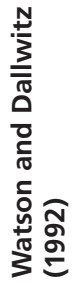

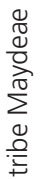

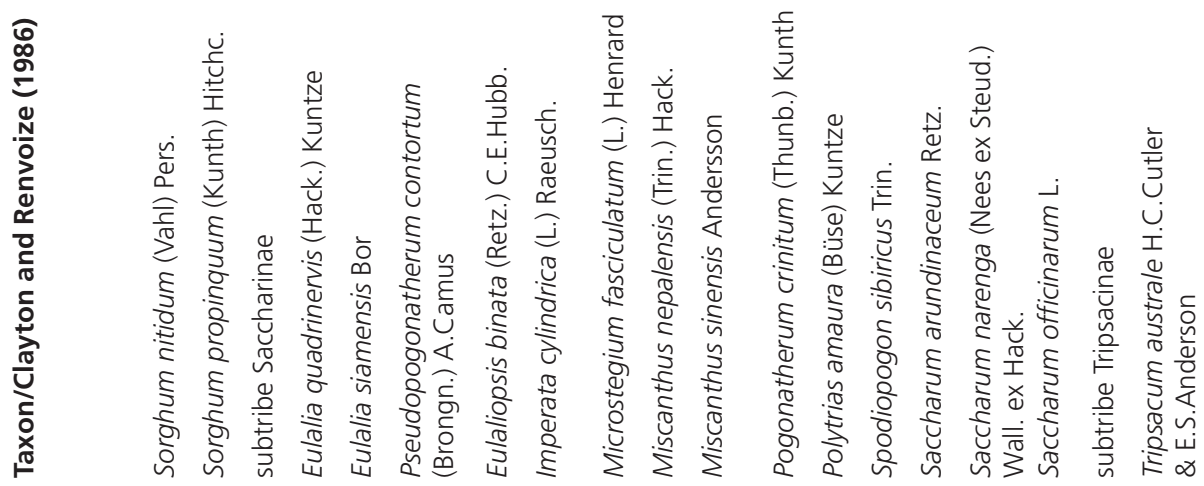




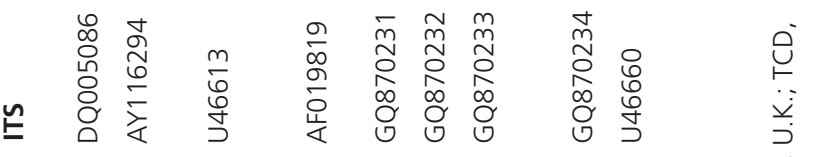

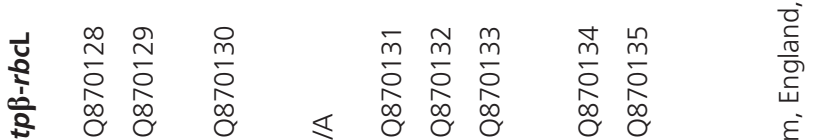

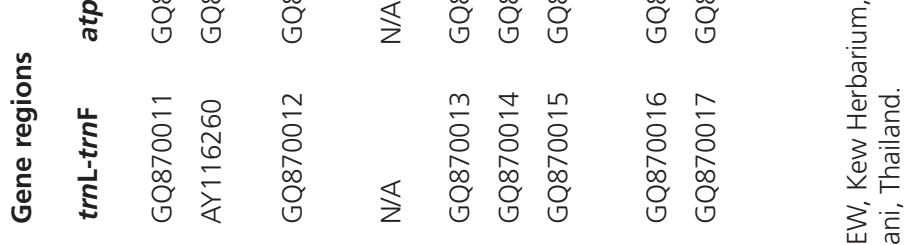

ᄒᄒ

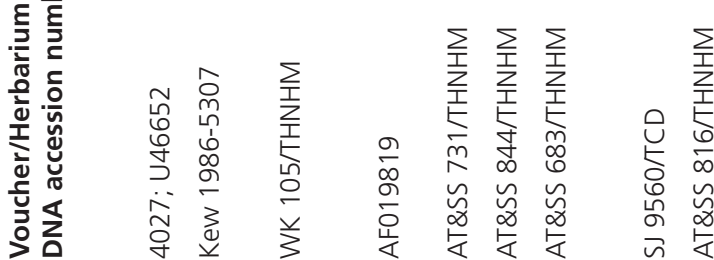

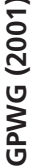

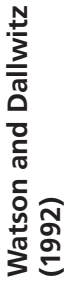

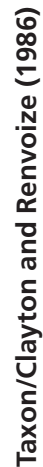

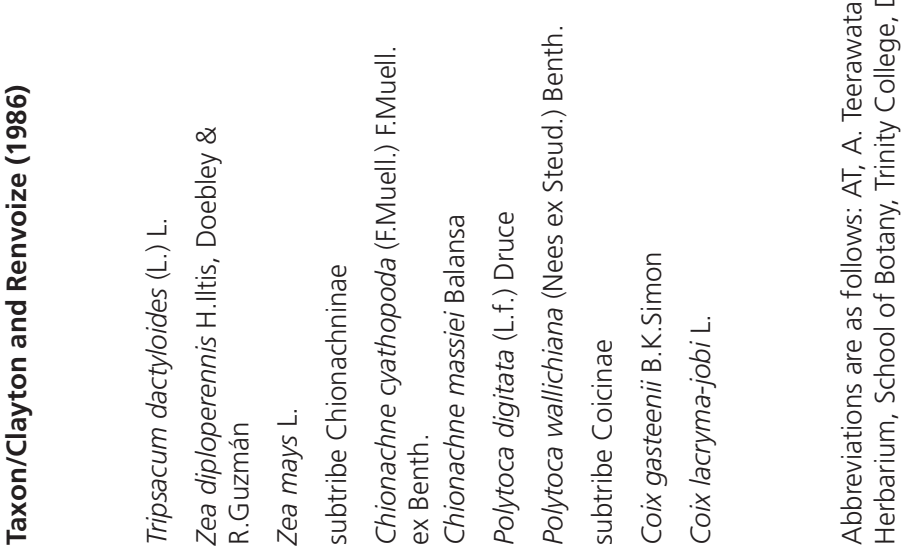

要

呵

弟苗

ज

जे

นัํํㅇ

范

3

ज衣

过

응

음

읃음

过

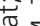

方至

安

妾 $\frac{0}{0}$

ธิ 
Appendix 2. Supplementary information.

Tree length: 1532

CI: 0.589

RI: 0.776

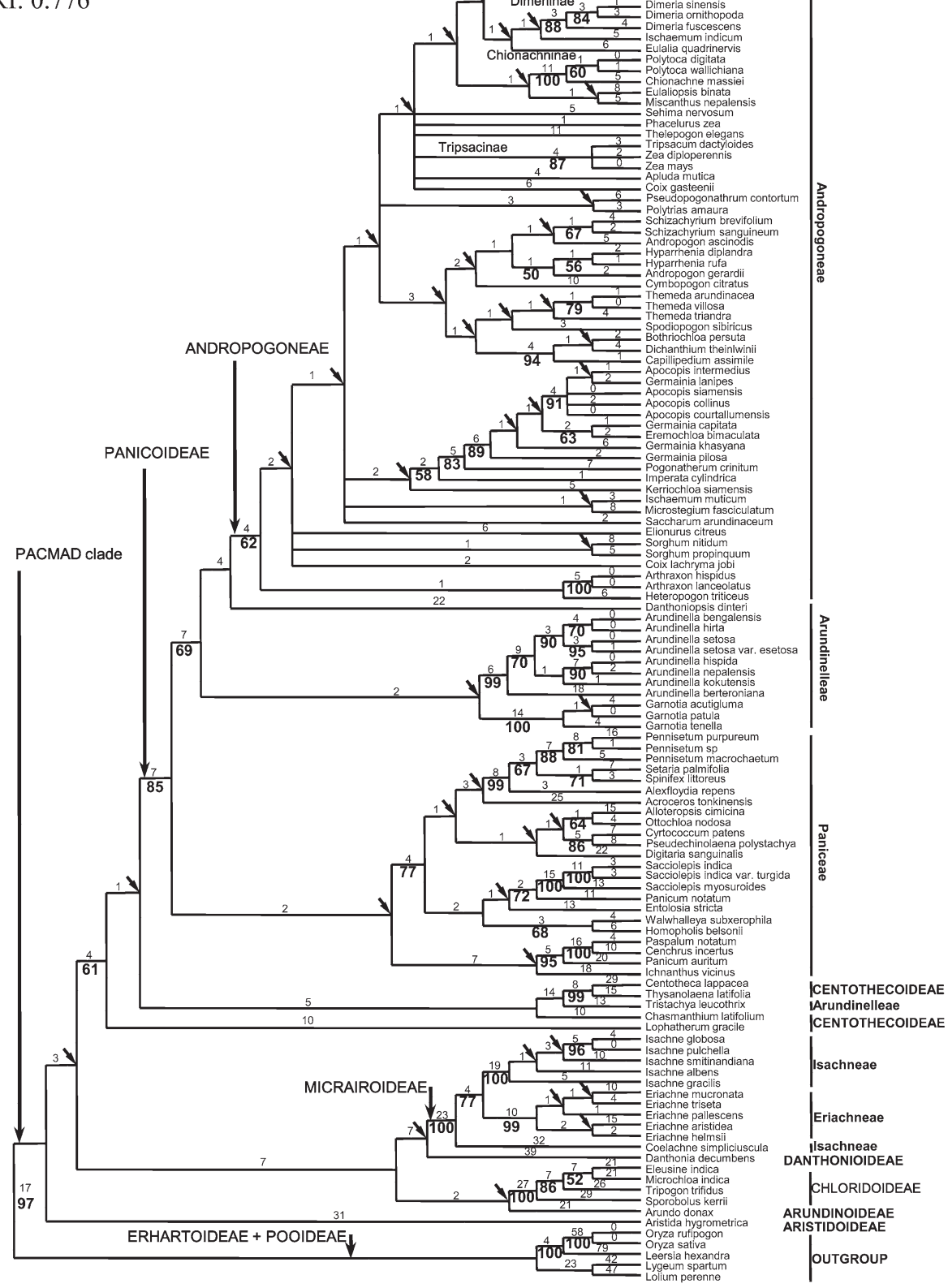

Fig. S1. One of 13,100 equally most parsimonious trees shown as a cladogram obtained from comparative sequence analysis of combined chloroplast DNA sequences. Values above branches represent the number of steps supporting each branch. Values below branches represent the bootstrap support above 50\%. Arrow heads represent nodes not found in the strict consensus. The PACMAD clade, the subfamilial and the tribal classifications (the column on far right) are according to GPWG (2001) and Clayton and Renvoize (1986), respectively. 


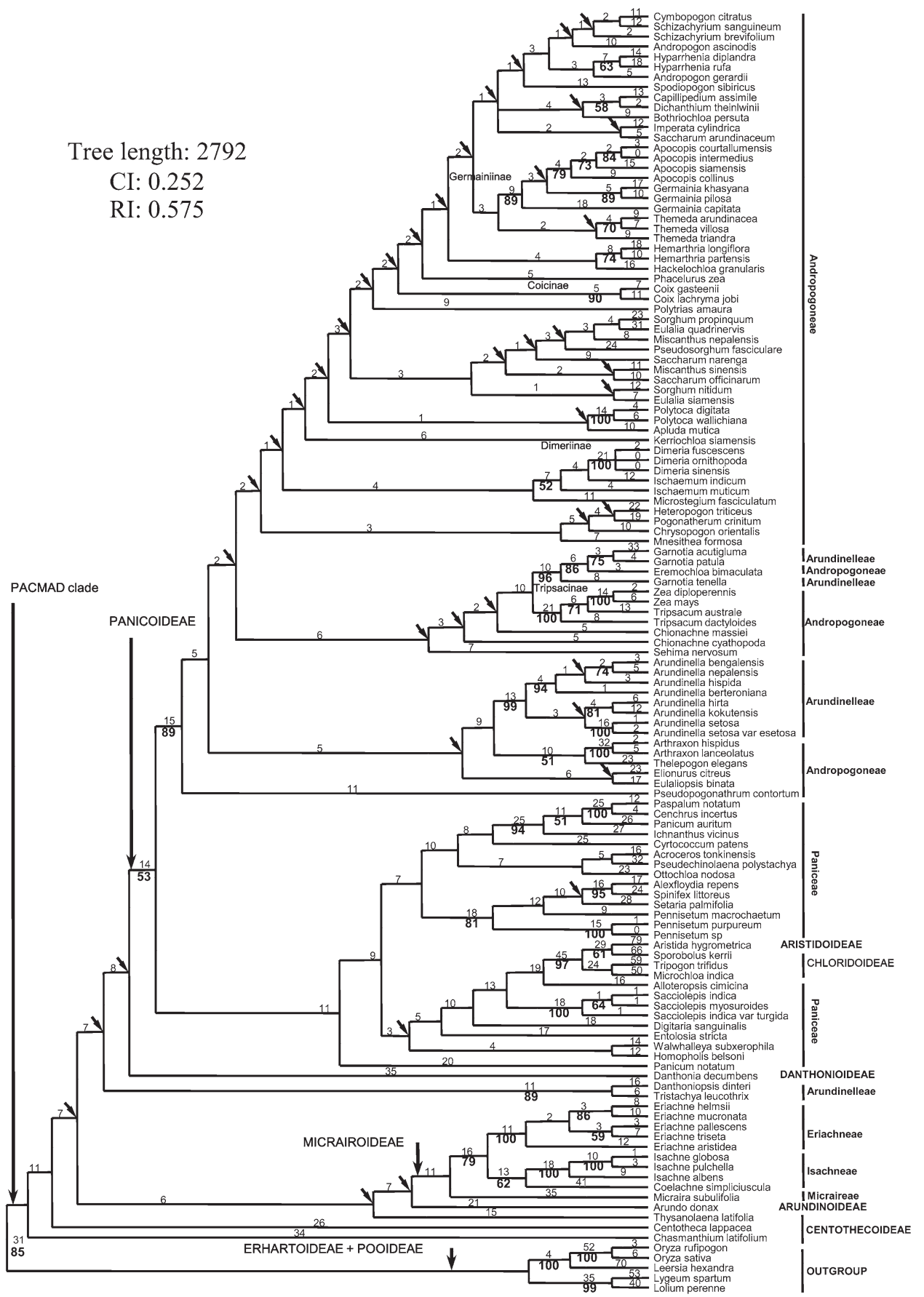

Fig. S2. One of 3,100 equally most parsimonious trees shown as a cladogram obtained from comparative sequence analysis of the ITS DNA sequences. Values above branches represent the number of steps supporting each branch. Values below branches represent the bootstrap support above $50 \%$. Arrow heads represent nodes not found in the strict consensus. The PACMAD clade, the subfamilial and the tribal classifications (the column on far right) are according to GPWG (2001) and Clayton and Renvoize (1986), respectively. 